\title{
The Leader as Catalyst \\ On Leadership and the Mechanics of Institutional Change
}

\author{
SUMON MAJUMDAR \\ SHARUN W. MUKAND
}

CESIFO WORKING PAPER NO. 2337

CATEGORY 2: Public CHOICE

JUNE 2008
An electronic version of the paper may be downloaded
- from the SSRN website: Www.SSRN.com
- from the RePEc website: Www.RePEc.org
- from the CESifo website: www.CESifo-group.org/wp




\title{
The Leader as Catalyst On Leadership and the Mechanics of Institutional Change
}

\begin{abstract}
Individual leaders have been central to the transformation of political institutions, organizations and many instances of social and economic reform. Why are some leaders able to take advantage of opportunities to successfully catalyze large-scale change while others fail? In this paper we argue that the key to understanding a leader's effectiveness lies in dissecting the symbiotic nature of the leader-follower relationship. While the expected dynamism of a leader attracts followers, at the same time, followers empower the leader and contribute to his dynamism. This two-way leader-follower interaction can endogenously give rise to threshold effects: 'small' differences in leader ability can have a large impact on the degree of effective leadership and dramatically alter the prospects for change. The framework also naturally allows us to explore when individuals may deliberately prefer to follow an ambitious leader with very different preferences rather than a leader with more congruent preferences. Moreover, by empowering the self-interested ambitious leader, such followership may make him a more effective agent of (both good and bad) change.
\end{abstract}

JEL Code: D72.

\author{
Sumon Majumdar \\ Department of Economics \\ Dunning Hall \\ Queen's University \\ Kingston, Ontario K7L 3NG \\ Canada \\ sumon@econ.queensu.ca
}

\author{
Sharun W. Mukand \\ Department of Economics \\ Tufts University \\ 305 Braker Hall \\ 8 Upper Campus Rd. \\ USA - Medford, MA 02155-6722 \\ sharun.mukand@tufts.edu
}

For comments and encouragement, thanks to Eli Berman, Tim Besley, Mark Harrison, Ian King, Masa Kudamatsu, Stephen Morris, Andrew Oswald, Dani Rodrik and numerous seminar participants. 
"Successful economic policy in developing countries is very far from being the product of pure forces of history - something that happens when it happens because its time has come. Far from it, in every case about which I have close knowledge, the policy would in all likelihood have failed (or never got started) but for the efforts of a key group of individuals, and within that group, one or two outstanding leaders.

Arnold Harberger (1993), Secrets of Success: A Handful of Heroes

\section{Introduction}

On 6 April, 1930, Mahatma Gandhi culminated his "Salt March" in the town of Dandi on the western coast of India. There, in defiance of the British monopoly on the collection of salt, he simply picked up a lump of natural sea salt. Within days, in a coordinated act of civil disobedience, not only Gandhi's followers in the Congress Party, but also millions throughout India did the same. It is widely agreed that this unique, collective act of non-violent protest was the first shot that eventually brought down the British Empire in India. Gandhi's skill at recognizing the effectiveness of civil disobedience and his choice of salt as a simple yet emotive symbol of communication was important. However, Gandhi's effectiveness in transforming a novel protest into a broad movement for change was also driven his ability to draw on a cadre of committed followers that he had attracted by this time (Dalton, 1993). Indeed, this synergy between a leader and his followers has been central to most movements of broad-based change. Lenin's ability to leverage his followers in the Bolshevik party was crucial in shaping the contours of Soviet political institutions, just as a group of committed guerillas empowered Fidel Castro to carry out the Cuban revolution. Similarly, no account of organizational transformation at GE can fail to give Jack Welch and his 'varsity team' of followers a central role. Yet, economists have paid relatively little attention to analyzing the role of leaders in bringing about broad-based institutional or organizational change. ${ }^{1}$

In this paper we take a step in this direction and ask: why are some leaders adept at seizing a 'window of opportunity' to successfully catalyze large-scale change while others fail? Our framework emphasizes the key nature of the two-way relationship between a leader and potential followers in having a dramatic, transformational impact on the prospects for change. However, such transformational leadership can be for the better or worse - for every leader such as Nelson Mandela there is a Robert Mugabe. Accordingly, our aim is to also examine within the same structure the issue of different types of leaders, their selection (Besley, 2005) and the type of changes that are brought about. In particular, we ask if individuals may prefer to become followers of a

\footnotetext{
${ }^{1}$ Hermalin (1998) is a prominent exception. In a signaling framework, the paper focuses on how a manager-leader can motivate a given set of followers to take a particular action.
} 
leader who is ambitious and unscrupulous or one with whom they have congruent preferences? Does followership empower or handicap attempts by such leaders at change - be it good or bad?

This paper addresses these questions within a unified framework of endogenous followership, leadership and mass participation. In certain domains, by virtue of their formal authority, leaders are assured that individuals have no choice but to follow the policies announced. However the exercise of such formal authority through contracts, decrees and diktat is typically much less relevant in cases of large scale change of the status-quo, be it of institutions, the social order or the overall economy. While a leader may initiate the process of challenging the status-quo, the success or failure of such attempted changes depends on how widespread is the popular response to the leader's initiative. Participation in successful mass movements for social or political change is typically voluntary and coordinated - be it the popular overthrow of the Shah in Iran, the participation in Martin Luther King's "March on Washington" or the response to Deng Xiaoping's "Southern Tour" to resuscitate economic reform. Accordingly, we emphasize that change in the status-quo occurs only through the voluntary and coordinated switch of actions by a large number of individuals. Indeed, it is in resolving this mass coordination problem across followers that the leader plays a crucial role. ${ }^{2}$ The leader's dynamism plays an essential part in not only spotting the right 'window of opportunity' for change, but also in communicating it to the population.

However, a leader's effectiveness in mobilizing participation is not just a function of his ability. Rather we emphasize that it is best understood by dissecting the two-way relationship between the leader and his followers. On the one hand good leaders attract a cadre of committed followers. In turn, having a cadre of committed followers empowers the leader. We show that leaders who are successful in attracting a core group of committed followers can be particularly effective in transforming the prospects for change. In part this is because such a group "....can be ordered out onto the streets at will.... to swell audiences, and campaign for him with extraordinary vigor and often at sacrifice to themselves. A leader can use such followers as a means of subtle or overt intimidation....He has in short, a most malleable instrument to use at will."(Willmer, 1984, p.184)

In our model, people choose to (endogenously) become followers by committing to follow more closely the leader under all circumstances. Doing so is costly and thus individuals will only become followers if they expect gains from following the leader. This creates a demand for leadership and (by empowering the leader) in turn affects the supply of leadership by the leader. In equilibrium, these two forces together determine the probability of successful change. We demonstrate that this dynamic leader-follower interaction may give rise to endogenous threshold effects for effective

\footnotetext{
${ }^{2}$ Evolutionary biologists such as Krause and Ruxton (2002) have emphasized that leadership is likely to have evolved in humans to solve coordination problems. According to Van Vugt (2006) "leadership originally emerged to solve simple coordination problems in group-living species and has an ancient phylogenetic history."
} 
leadership; only if a combination of the leader's ability and the underlying structural conditions satisfies a certain threshold, is change possible. Slight differences in either can lead to dramatic differences in the probability of change. Thus even under identical structural conditions, there may be large differences in the effectiveness of leaders of very similar ability. In particular, if the leader's ability is higher than the (endogenous) threshold, he attracts a core group of committed followers which is of sufficient size to encourage participation by even non-followers in the process of change. It thus highlights the critical role that the Bolshevik Party party had in boosting Lenin's effectiveness or the Nazi Stormtroopers in transforming Hitler's political prospects.

Public perceptions of the leader's ability and the general outlook for the prospects of change play an important role in determining a leader's actual effectiveness at catalyzing change. When these beliefs are pessimistic, change is harder to achieve. Under these conditions, only leaders of exceptional ability can overcome the (endogenous) threshold to bring about change. By disentangling the effects of public perceptions versus actual leader ability in determining the probability of successful change, our framework sheds light on the classical debate between the 'structuralist' and the 'Great Man' schools of historical change. ${ }^{3}$ We demonstrate that public perceptions determine the threshold for effective leadership. However, once this threshold is crossed, the leader's actual ability helps determine the overall probability of change. Thus, this conforms with what is popularly known as the "Weberian" view which stresses the importance of individual leader characteristics, but only under the right structural conditions.

The existence of threshold effects suggests that a leader can have an independent and firstorder role in affecting the trajectory of a country's institutional evolution. Slight differences in the quality of leaders of two otherwise similar countries can lead to significant differences in the institutions adopted (or not). Given the importance of institutions for a country's development ${ }^{4}$, this implies that countries need not be trapped by their institutional inheritance. Rather leaders can serve to transform some institutions - thus institutions need not be destiny.

When the leader's preferences are not aligned with that of the broader population, effective leadership is even more difficult. This is because in a divided polity, a leader faces a "credibility gap". Individuals fear being misled into making a costly investment and following a leader whose preferences are not congruent with theirs. However, our framework highlights two additional effects at work. Self-interested, ambitious leaders can be ruthless, unscrupulous and are likely to leave

\footnotetext{
${ }^{3}$ The 'structural' view (its earliest proponents were perhaps Tolstoy and Marx; Gilpin (1981) is a more recent systematic exposition) emphasizes historical forces as determining outcomes, with individuals having a marginal role. On the other hand, the 'Great Man' school (Carlyle (1841) was an early exponent; Kissinger (1968), Ionescu (1991) are among more recent proponents) views individual leaders as having decisive influence on outcomes.

${ }^{4}$ See for example, Acemoglu et. al. (2005), Dixit (2004) and Rodrik et. al. (2005).
} 
no stone unturned in their drive to identify any 'window of opportunity' that helps them achieve their goals - be it through narrow self-interested change or for a broader gain. The role of this "ambition effect" in helping bring about change is perhaps best illustrated by Lyndon Johnson's role in the U.S. Senate. Once Johnson realized that it would help pave the way to the Presidency, his ambition and energy was instrumental in 'discovering' a solution to the political impasse and pushing through the Voting Rights Act of 1957. Caro (2002, pp. 862) describes that

.....And now, at last, in 1957, it was.... For at last this leader of men would be leading, fighting, not only for himself but for a great cause. This man who in the pursuit of his aims could be so utterly ruthless - who would let nothing stand in his way; who, in the pursuit, deceived, and betrayed and cheated - would be deceiving and betraying and cheating on behalf of something other than himself: specifically, on behalf of the sixteen million Americans whose skins were dark.

Accordingly, as a by-product of this "ambition effect", self-interested leaders may also discover socially beneficial opportunities for change. The effectiveness of an ambitious leader is further reinforced by an additional effect that we identify in terms of followership for such leaders. Self-interested ambitious leaders will typically catalyze change that is personally beneficial, quite irrespective of whether or not it adversely affects the wider populace. This gives an individual a further incentive to become a follower in order to insulate oneself against adverse changes. ${ }^{5}$ This "insulation" effect reinforces the "ambition" effect and makes the self-interested leader a more effective agent for change. However, given that such leaders lack credibility and cannot be trusted to always bring about socially beneficial change, it is a priori not clear that a majority of the populace will select such a leader. Quite strikingly, we show that under certain circumstances an ambitious leader with preferences differing from the majority maybe preferred to a leader whose preferences are congruent. While the overall probability of change is higher under an ambitious, self-interested leader, such change may be for better or for worse.

Related Literature: Leadership plays an important role in all forms of human (and primate (Brown, 1991 and Wilson, 1975)) societies. Indeed despite being poorly understood (see Burns, 1978 for an overview), leadership has been relatively understudied by economists. An important early contribution is Hermalin (1998) who in a signaling framework, emphasizes the importance of a leader's example in getting a given team of individuals to follow. While his model captures well the leader's initiative in the overall process, it does not consider the decision of individuals to endogenously invest in followership and thereby empower the leader. In our model, this two-way

\footnotetext{
${ }^{5}$ Brustein (1996) and Kravchenko (1947) document how prudent self-insurance was one of the factors driving individuals to become members of the Nazi (or Communist) party when Hitler (respectively, Stalin) came to power.
} 
interaction is crucial in determining the effectiveness of a given leader. Rotemberg and Saloner (1993) capture leadership by analyzing how the degree of empathy a leader has for the subordinate can alter the latter's incentives. However, they do not consider the role of followership and its feedback onto the leader's dynamism and on other agents. While Besley and Ghatak (2005) do not directly address the issue of leadership, their analysis of motivated agents shares some aspects of the leader-follower relationship studied here. We instead focus on the incentive of potential followers to make themselves more or less 'motivated', and its effect on the leader. Aghion and Tirole (1997) highlight the impact on incentives of the decision by a principal with formal authority to delegate real authority to a subordinate. Our framework instead emphasizes the importance of (subordinates') followership in transforming the leader's formal authority to initiate change into effective leadership (i.e. into real authority).

The literature on institutional change has recognized the importance of leaders in determining the trajectory of a country. For instance, Acemoglu, Johnson and Robinson (2003) acknowledge the role of Seretse Khama in laying the foundations of growth in Botswana. Jones and Olken (2005, 2006) are the first to empirically demonstrate using a cross-country study, that leaders matter for growth and institutional change. Recent work by Acemoglu and Robinson (2006) on political transitions has been very influential. Their work emphasizes the role that lack of commitment and exogenous shocks play in affecting the ruling elites' cost-benefit calculus of persisting with the status-quo political set-up. Our framework can be viewed as providing a micro foundation for the process of how such stochastic shocks get translated into political change. In our framework, coordination is not automatic but occurs as a result of the leader's ability in recognizing a window of opportunity and convincing the populace of the benefits from seizing it. It highlights that although opportunities for change may come about, not all societies are able to capitalize on them. Some, especially those with a low quality of leaders may remain trapped by their institutional inheritance.

The study of leadership and change has been pursued in much greater detail in disciplines other than economics. For instance, the study of leadership is a central theme in many studies of organization behavior and management (see Bass, 1990 and Northouse, 2004). Similarly, it has been explored in political science (Burns, 1978), international relations (Young, 1991) and social psychology (Van Vugt and De Cremer, 1999), among other fields.

We start by describing the elements of the basic model in the next section. In Section 3.1 we analyze the equilibrium when the preferences of the leader and the populace are congruent. We relax this assumption in Section 3.2 with the leader-follower preferences being not perfectly aligned. Some applications are discussed in Section 4, and Section 5 details some particular instances of leadership and change. Section 6 concludes. 


\section{The Model}

We develop a simple model to capture the two-way relationship between followers and a leader and the impact of this relationship on successfully engendering change. The model consists of the following key elements. One, the mechanism for successful change which requires the coordinated switch of actions by a large number of individuals under the right circumstances; two, the leader's role in identifying suitable opportunities for change and spurring individuals to take advantage of such opportunities; three, followership, which is characterized by the willingness of individuals to respond to a leader's call for action. A key aspect of our framework is the interdependence between the followers' demand for leadership and the leader's supply of leadership, which together help determine the probability of successful change.

\section{Uncertainty and Coordination:}

While many changes such as an alteration of the tax rate or the wage, can be unilaterally implemented by a leader or manager through fiat, broad-based economic, institutional, organizational or social change is far more difficult to achieve. Such change often requires a coordinated switch in the beliefs and actions of a large number of individuals with possibly differing preferences, costs and priors, and is typically difficult to achieve. Not only does an individual agent lack information about whether others also plan to switch, but further may even be uncertain if underlying conditions are such that change is optimal to begin with.

To capture uncertainty about whether or not the underlying conditions are appropriate for change, we assume that there are three possible states of nature: $B, G_{0}$ and $G_{1}$. State $B$ is one in which change is never possible; in this state, even a coordinated change of actions will not only never succeed, but also results in all participants (including the leader) becoming worse off, earning a very large negative utility. This is meant to capture the idea that under some conditions, any attempt at change is futile and costly and should not be undertaken. ${ }^{6}$ The prior on the states being $B, G_{0}$ and $G_{1}$ are $1-\alpha, \alpha(1-a)$ and $\alpha a$ respectively.

In states $G_{0}$ and $G_{1}$, change is possible but requires coordinated mass action. We assume that the probability of successful change in either of these states is given by $\frac{1}{\theta} p \cdot m^{\theta}$, where $m$ is the fraction of the populace participating in the process, $\theta>0$, and $p \in(0,1)$ is a parameter that denotes the degree of uncertainty inherent in the process. This formulation captures in a stylized manner two plausible aspects of the process of regime change - one, that it is stochastic and two, it is more likely to occur when there are more active participants. The parameter $\theta$ captures the impact of the degree of complementarity amongst participants on the probability of success;

\footnotetext{
${ }^{6}$ In effect, this assumption rules out the possibility of a 'sunspot' as a spontaneous coordination device.
} 
when $\theta$ is small, the marginal effect of increased participation $m$ is large. For simplicity, in most of the analysis that follows, we assume $\theta=1$ and thus the probability of successful change equals p.m. In section 3.1.1, we relax this assumption and examine the implications of differences in the degree of complementarity $\theta$ on the qualitative results.

While change is possible in both states $G_{0}$ and $G_{1}$, they differ in terms of the distributional consequences of successful change. The population is assumed to belong to one of two groups the majority (group $M$ ) or the minority elite (group $E$ ). State $G_{1}$ is a situation in which the gains from successful change are wide-spread and accrue to any individual who is an active participant in the process, irrespective of his or her group. In this state, we denote by $G>0$ the gain from successful change to a participant from either group; for non-participants, this is zero. Such gains could be psychological, arising for instance from the satisfaction of participating in the overthrow of a hated autocrat, or the status rewards from being a "freedom fighter" or a party official. Equivalently the rewards may be material, in the form of preferential access to scarce resources accruing to members of a successful political party or revolutionary group, or being the early adopter of a successful technology. ${ }^{7}$ In contrast, in state $G_{0}$, the gains from change accrue to a much narrower segment of the population, namely, only to participants from the elite group $E .^{8}$ In this state, while participants from the majority group incur the cost and raise the chances of success, they enjoy none of the gains from change. Accordingly, popular perception of the leader's interests being aligned with one group or the other has important consequences for his credibility (and hence the degree of followership). For simplicity, we assume that the minority group is of zero mass (while the majority is of mass 1). We will discuss below how relaxing this assumption does not qualitatively affect most of our results (footnote 26 characterizes the equilibrium in the case of a small but non-zero mass of group $E$ ).

We have normalized the payoff from maintaining the status-quo as 0 , and have also taken the gains to non-participants from successful change as being 0 . This is largely to reduce unnecessary notation. The analysis would not change if instead we denoted the gains to non-participants from successful change by say $\Delta$, and $G$ as the additional gains enjoyed by participants in the process of change that is over and above $\Delta$.

While change is possible in some states and not in others, at an individual level what makes it particularly difficult is the lack of information about the underlying state of the world. Indeed,

\footnotetext{
${ }^{7}$ Ferguson and Voth (2008) document that firms that had 'close and early connections' with the Nazi Party in Germany during the thirties, reaped large financial rewards. Such early 'follower' firms outperformed the stock market to the tune of 5 to 8 percent.

${ }^{8}$ Alternately, it could also be interpreted as a state in which the gains from change accrue only to the leader (e.g. consolidation of political power), while the population gain nothing. For example, state $G_{0}$ could require a process of change that involved a large scale destruction of resources that is unlikely to be of benefit to the majority.
} 
in the absence of information, the large downside risk if the underlying state turns out to be $B$ results in a lack of action and thus the persistence of institutions and the prevalence of the status quo. This is where we introduce a role for a leader.

\section{Leadership and Information:}

While the general populace lacks information about the underlying state of the world, we assume that there is an exogenously given leader who is in a position to invest in acquiring such information and conveying it to the masses. For instance, in the case of political change, it could be information that the ruling regime is currently weak and vulnerable, or in the instance of economic reform, it could be about the state of the global market. However, ascertaining whether there exists a suitable 'window of opportunity' is not easy for the leader to do (Hirshman, 1970). ${ }^{9}$ It requires a mixture of skill and instincts as well as initiative as exemplified in Lyndon Johnson's ability to spot and utilize a unique 'window of opportunity' to push through the Voting Rights Act of 1957 or Lenin's perfect timing in his decision to launch the October Revolution. Accordingly we assume that if the leader expends resources $e(i)=l i^{2} / 2$, then with probability $i$ he learns perfectly the state of nature, while with probability $1-i$, he learns nothing. On learning of a right opportunity, the leader next needs to convey this information to the populace. To capture the leader's ability at communication, we denote by $\tau \in(0,1)$ the probability that any member of the population receives the leader's message. The population is assumed to be a continuum so that equivalently $\tau$ is also the fraction that receives the leader's message. Thus the two parameters $l$ and $\tau$ capture two aspects of the leader's ability: his dexterity at identifying the right opportunities (a smaller $l$ ), and his skill at effectively communicating with the populace (a higher $\tau$ ).

While the model here focuses on the leader's decision to expend effort in acquiring information about the underlying state, we can easily use it to analyze other activities of the leader too, such as the intensity of his communication and persuasion of others to invest in change. For instance, one could alternately formulate (with similar qualitative results) the leader's choice variable as the amount of effort spent at communicating information, with $i$ being the fraction of the populace that receives his message if he expends resources $e(i)$.

A second aspect of the model also deserves comment. Our framework allows us to distinguish between a leader's formal authority and leadership, the probability that the leader is likely to bring about change. While the leader here is one by virtue of his position i.e. is the only one

\footnotetext{
${ }^{9}$ Indeed, Hirshman (1970) argues that it is an essential aspect of leadership. For instance, when discussing the example of Carlos Lleras Restrepo, Colombia's 'reform-mongering' President in the sixties, he argues that good leaders have "the ability to perceive change when most of one's contemporaries are still unable to do so.... that would enable a leader to take advantage of new opportunities as soon as they arise."
} 
in a position to acquire and communicate information, this formal authority in and of itself does not translate into catalyzing change. Instead effective leadership is a function of not just good information and the underlying structural conditions, but crucially also dependent on individuals' willingness to respond to the leader in challenging the status-quo. As we show below, even under suitable circumstances, only certain leaders will exhibit effective leadership in the sense of being able to successfully catalyze change.

To capture the leader's incentives in the simplest manner, we denote by $L_{s}$ the leader's payoff from successful change in state $G_{s}, s \in\{0,1\}$. This payoff could be either a monetary or political gain as a result of successful change. The following restriction on gains $L_{s}$ and costs $l$ ensures that the choice variable $i$ (which is the probability that the leader acquires information about the present state) is always less than 1.

Assumption 1: $\alpha p \tau L_{s}<l$

Given that there are two groups in the economy, the majority $M$ and minority elite $E$, the leader's interests could be aligned with either group. Notice that the above formulation allows us to easily capture such differences in preferences. A "benevolent" or "non-partisan" leader here is one who cares about the welfare of the majority and thus would like to see change coming about only in state $G_{1}$ where the benefits are wide-spread and accrue to all groups. Thus for such a leader we assume that $L_{1}>0$ and $L_{0}=0$. On the other hand, a leader may have preferences aligned with the narrow elite or could be self-interested in the sense of pursuing modes of change that benefit only himself. Such a "self-interested" or "elitist" leader would like to see change enacted even in state $G_{0}$, where only the elite (and himself) gain while all bear the cost. Accordingly, such a leader is assumed to have $L_{1}>0$ and $L_{0}>0$. In our analysis below, we will in turn consider each of these two types of leaders.

Since successful change requires coordinated participation in the process by a large number of individuals, we now describe the costs and benefits from participation.

\section{Participation and followership:}

There exists a unit mass of individuals, some of whom may choose to participate in the process of changing the status-quo. While participation holds the promise of a reward (as described before), it also involves incurring some costs. The degree of an individual's response to a call for action by the leader will obviously depend on her cost of participation as well as the perceived benefits. A natural way to introduce followership in our framework is to assume that individuals can ex-ante invest in lowering their ex-post cost of participation. Individuals who make this early investment are more likely to have a lower participation cost in the future and are thus more likely to participate when called upon to do so by the leader. In other words, such individuals are 
"followers" ${ }^{10}$ In terms of the model, we assume that with probability $y$, the personal cost $c$ of participating in the process is 0 , and with probability $1-y$, this cost $c$ is drawn from a uniform distribution with support $\left[0, c_{H}\right]$. We will assume that $c_{H}$ is high enough so that not all people participate in the process of change even in the best possible circumstances:

Assumption 2: $p \tau G<c_{H}$

Depending on the context, these participation costs can take different forms. For instance, an attempt to bring about a revolution against an autocratic government requires individuals to take costly actions in the form of participation in street protests, boycotts, and even armed struggle. Such acts involve the possibility of arrest and physical harm and also direct costs in terms of opportunities foregone. In this case, undergoing arms or ideological training before-hand, joining a political party, organizing one's matters and forsaking other forms of employment, reduce the ex-post cost of participation and make one more likely to participate in the revolution if and when it comes about. Alternatively, a country's attempt at liberalizing the economy or joining the WTO is likely to be successful if domestic firms have already made the costly investment to modernize and increase productivity. Given any convexity in adjustment costs, firms that upgrade their technology early instead of waiting till the end moment, are likely to have lower adjustment costs, and consequently a higher overall payoff.

Accordingly in the model we assume that people can invest before-hand in $y$ i.e. in lowering their ex-post cost of participation. The cost of investing $y$ is given by $f(y)=k y^{2} / 2$. This formulation provides us with a simple way to distinguish between followers and other participants. We label as "followers" those individuals with a low cost $c=0$ of participation in any change, as they participate whenever called upon to do so by the leader. On the other hand, individuals with costs drawn between 0 and $c_{H}$ decide whether or not to participate depending on their own realized costs as well as their expectations of the movement succeeding - these are the "non-followers". While a fraction of this group may participate in the process, their decision to follow the leader's call for action is not automatic and is contingent on other factors. ${ }^{11}$

Dramatic institutional change such as the onset of democracy, the extension of civil rights or revolution of any kind typically involves numerous participants. This distinction between "followers" and the "non-follower" participants is a simple way to emphasize the differences between different kinds of participants that is common in many social and political movements for change.

\footnotetext{
${ }^{10}$ All that is required is that the (expected) payoff is higher, the earlier an individual makes a commitment. This payoff can be either pecuniary or even non-pecuniary in the form of more status and authority post-regime change.

${ }^{11}$ While the followers here are modeled as those with (endogenously) lower participation costs $c$, they could also be thought of as those who have psychologically adopted the leader's ideology or invested in learning his "language" and thus require less persuasion by the leader to participate.
} 


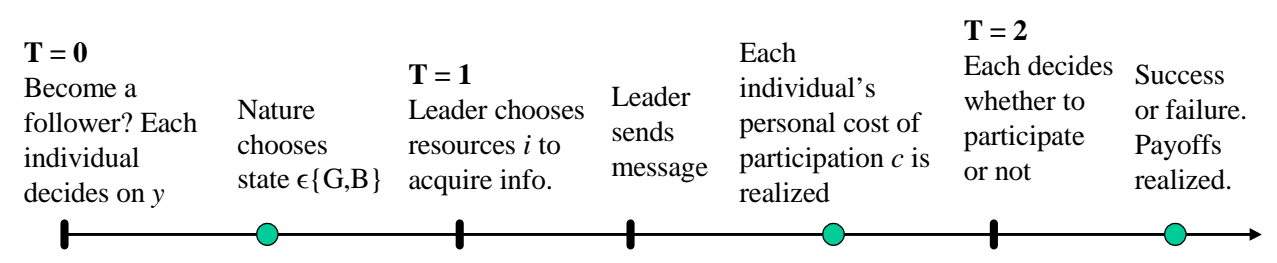

Figure 1: Timing of events

The followers can be considered to be the committed and loyal supporters who offer unconditional support to the leader and play a pivotal role in spurring the leader towards action. ${ }^{12}$ Depending on the kind of change being analyzed, these followers can be members of Mandela's African National Congress, Lenin's Bolshevik Party or Jack Welch's 'varsity team' of managers.

Timing of events. Figure 1 gives a diagrammatic depiction of the timing of events. Initially, at date $T=0$, each member of the population decides how much $y$ to invest in reducing his or her cost of participation. A higher $y$ at this stage denotes a greater degree of followership, as one is then more likely to respond positively to the leader's call for participation ex-post. The state of the world is subsequently realized, and at date $T=1$ the leader invests $i$ in acquiring information about it. If he receives information, the leader communicates this to the populace. People's personal costs of participation are then realized, and at $T=2$, each decides whether or not to participate in the process of bringing about change. Depending on the state of the world and the number of people participating, change occurs or not and payoffs are realized.

\section{Leadership and Change: Equilibrium Analysis}

As pointed out earlier, the framework described above seeks to capture the dynamic between a leader and his followers and its overall consequences for large scale change such as economic reform, institutional and organizational transformation. In determining the leader's effectiveness at catalyzing change, one has to account for not just his ability but also his preferences. As described above, depending on the value of $L_{0}$, the leader may have objectives aligned with the

\footnotetext{
${ }^{12}$ Hitler saw the advantage of such a fanatical band of followers and recognized the power of his Nazi party as early as 1921. When talking about the Storm troopers, Hitler said "the young movement was to supply what the others lacked: a volkisch movement with a strictly public base, including the broadest masses, welded together by iron-hard organization, filled with blind obedience and inspired with brutal determination, a party of battle and action." For instance, Hitler's Storm troopers could be either encouraged or "restrain(ed) from action or violence if it seemed advantageous." (Willmer, 1984, pp. 184).
} 
majority or with the minority elite, and this may impact individual participation and followership decisions. In our analysis below, we consider each case separately.

\subsection{Leadership and Followership under Congruent Preferences}

We begin by exploring the leader-follower dynamic in the case where there is perfect alignment of preferences between the leader and the majority i.e. the case of a non-partisan or benevolent leader. Such congruence could arise either because the leader belongs to group $M$ and/or is non-partisan by nature or because underlying political considerations force the leader to only take into account the welfare of the majority. For example, if the political framework is one where the majority $M$ has the power to determine whether or not the leader is re-selected, we can expect a closer congruence in the objectives of the leader with those of group $M$. To not introduce additional issues of imperfect information, we assume the leader's preferences are common knowledge. Note that in this case, both the leader and potential participants only gain in state $G_{1}$; thus issues of the leader misleading or signaling by example (as in Hermalin, 1998) do not arise here.

Participation: In analyzing the equilibrium, let us start from period $T=2$ where each individual knows his own opportunity cost of participation $c$ and decides whether or not to participate. For an individual who has not received any message from the leader, given that there is a very large negative utility to attacking in a bad state, he will not participate irrespective of his cost.

Thus the only consideration is for individuals who have received message of a good state from the leader. Since the leader here is a benevolent one, all such individuals will infer that the state must be $G_{1}$ as a benevolent leader will never issue a call for action in states $B$ or $G_{0}$. If this individual faces zero cost of participation, as is the case for a committed follower, he will indeed participate. For an individual with a positive $\operatorname{cost} c$, he will have to weigh the costs and benefits from participation in making his decision. If his expectation about how many other people will participate is $m^{e}$, this individual will also choose to participate only if $c \leq p G m^{e}$. Thus the marginal participant is one whose participation cost is given by $c^{*}=p G m^{e}$.

Given the leader's ability $\tau$ at communicating his message, a fraction $\tau$ of the populace receives it. Of this, a fraction $y$ are committed followers and have zero realized cost of participation and surely do so; among the rest, only those with costs less than $c^{*}$ participate. Thus aggregating across all individuals, the total mass of people who participate in the process is given by:

$$
m=\tau\left[y+(1-y) \frac{c^{*}}{c_{H}}\right]
$$

In equilibrium, individual expectations about aggregate participation are realized. Thus, incorporating this into the marginal participation decision gives the equilibrium cut-off cost $c^{*}$ for 
participation:

$$
c^{*}=p \tau\left[y+(1-y) \frac{c^{*}}{c_{H}}\right] G
$$

For a given level of followership $y>0$, this equation gives the degree of participation $c^{*}$ by non-followers, and is represented by the increasing curve $P$ in figure $2(\mathrm{a})$ - the participation curve.

The following proposition shows that $c^{*}$ is unique and analyzes some of its properties.

Proposition 1 For any given level of followership $y>0$, there is a unique level of participation $c^{*}$, which is determined from equation (1). Increases in $y, \tau, p$ or $G$ or a decrease in $c_{H}$ raise the probability of change in state $G_{1}$.

Proof. See Appendix.

An increase in the number of followers $y$ or better communication ability of the leader $\tau$ or a decrease in $c_{H}$ raise the mass of participants for a given $c^{*}$, thus raising the chances of success. This encourages more marginal participants thereby raising $c^{*}$. As the overall probability of change is related to the total mass of participants in the process, variations in the underlying parameters that raise $c^{*}$ also serve to increase the probability of successful change. For instance, in the presence of a leader who is perceived to be an effective communicator, each individual expects the leader's message to reach more people. Thus each is more encouraged to participate and hence overall there is greater participation (and a higher chance of success) in bringing about change.

It is interesting to note some additional features of this solution. As $y$ increases, $c^{*}$ increases. In other words, as the number of committed followers increase, so too does participation by the rest of the population. Thus there is complementarity between followers and mass participation. Note also that when $y=0$, the only equilibrium involves $c^{*}=0$ i.e. no possibility of change ${ }^{13}$. Thus a core group of committed followers is necessary to have any positive chance of successful change. The nature of this dynamic between an individual's followership decision and leadership will become more evident in our analysis of the overall equilibrium below.

Leadership: Next we move back to period $T=1$ where the leader decides on how much effort $i$ to devote in trying to discover the underlying state. If the benevolent leader uncovers no information or discovers that the conditions are not right (i.e. in states $G_{0}$ or $B$ ), he will not send out any message urging people to participate as there is zero probability of success. On the other hand if the underlying state is good (i.e. $G_{1}$ ), the leader issues a call to initiate change. Of course, whether or not people will act on the leader's message depends on their own personal costs as well as their expectation about action by others (as described above).

\footnotetext{
${ }^{13}$ This is because under Assumption 2, the equilibrium condition $p \tau G \frac{c^{*}}{c_{H}}=c^{*}$ cannot hold for any $c^{*} \in\left(0, c_{H}\right]$.
} 
Taking the participation decision of the populace in response to a call for action as given, the leader chooses his effort $i$ at discovering the underlying state to maximize $\alpha a i p m^{e} L_{1}-e(i)$. The first-order condition for the problem yields the leader's degree of initiative:

$$
\alpha a p m^{e} L_{1}=\alpha a p \tau\left[y+(1-y) \frac{c^{*}}{c_{H}}\right] L_{1}=l i
$$

As the leader expects a greater degree of response $m^{e}$ by the populace to his message, it encourages him to expend more resources into discovering suitable windows of opportunity. In other words, the supply of the leader's initiative is increasing in the number of committed followers $y$ as well as the expected participation of the "non-followers" in the general populace (given by $c^{*}$ ). It is also increasing in the rewards from change, either for himself (a higher $L_{1}$ ) or for the participants (via an increase in $c^{*}$ ) or an increase in his communication-ability $(\tau)$. The effect of $\tau$ on the leader's incentives can be both direct as well as indirect. First, the marginal rewards from increasing effort at discovering the underlying state is larger for a leader who can reach a bigger audience - the direct effect. This is reinforced by an indirect effect - namely, expectations of a larger fraction of the population receiving the leader's message encourages increased participation by non-followers (i.e. a higher $c^{*}$ ), which again feeds back to the leader investing more in $i$.

Followership: Finally, we move back to the initial period $T=0$ to analyze the decision by individuals to invest resources $y$ in becoming followers. Recall that a higher $y$ lowers the expected cost of participation in the future, and thus by investing in $y$, people commit themselves to more closely following the leader when called upon to do so. Of course, this decision to invest in followership depends on the expectations about the outcomes to follow in the subsequent periods.

To compute the expected payoff from investing $y$, note that in period $T=2$, an individual participates in the process of change only if the leader's message is received (which occurs only if the leader uncovers the state $G_{1}$ ) and if her cost of participation is either 0 or below $c^{*}$. Investing in followership (a higher $y$ ) helps lower the expected participation cost in the future. With probability $y$, this cost is 0 , while with probability $1-y$ it is distributed between 0 and $c_{H}$. Denoting by $V$ the expected gains from participating, an individual's payoff from investing $y$ is thus:

$$
\alpha a i \tau\left[y V+(1-y) \int_{0}^{c^{*}}(V-c) \frac{d c}{c_{H}}\right]-f(y)=\alpha a i \tau\left[y c^{*}+(1-y) \frac{\left(c^{*}\right)^{2}}{2 c_{H}}\right]-k \frac{y^{2}}{2}
$$

as $V=p m^{e} G=c^{*}$ (from (1)). Optimizing with respect to $y$ gives the first-order condition:

$$
\alpha a i \tau\left[c^{*}-\frac{\left(c^{*}\right)^{2}}{2 c_{H}}\right]=k y
$$


The above equation (4) gives the level of individual investment in followership $y$ for a given level of participation $c^{*}$ and leadership effort $i$. We label this the followership curve and it is represented by the curve $F$ in figure 2(a). In the above relationship, note that for any given level of participation $c^{*}$, the degree of followership $y$ is increasing in the level of initiative $i^{e}$ that is expected from the leader. As analyzed in equation (2), the feedback is in fact two way; a higher level of followership $y$ has a positive effect on the resources $i$ that is put forth by the leader also. Furthermore, an increased number of committed followers encourages participation by the rest of the populace, raising $c^{*}$. However, as the above equation shows, there is a reverse effect too: as $c^{*}$ increases i.e. as general participation rises (thereby increasing the chances of success), it enhances the incentives for any individual to become a committed follower.

While the above three individual decisions of participation, followership and the leader's initiative satisfy intuitively simple comparative statics properties, our objective is to focus on the interaction between the three decisions and how that translates into the overall prospects for successful change. This is what we do next.

Overall equilibrium: In this game, there always exists a no-action status-quo equilibrium in which no one invests in $y$ i.e. everyone chooses $y=0$, following which (from (1)) $c^{*}=0$ i.e. no one participates, and $i=0$. Anticipating this, the choice of $y=0$ at the initial stage is a rational response. In this equilibrium, there is no probability of change and the status-quo is retained.

To investigate interior equilibria, one needs to combine the ex-ante followership decisions of individuals with the leader's initiative decision in period $T=1$ and the participation decision of non-followers in period $T=2$. While the Appendix contains the details, here we outline the steps required to obtain the overall equilibrium. Recall that equation (1) (curve $P$ in Figure 2(a)) gives the degree of participation $c^{*}$ by non-followers for a given level of followership $y$, and that equation (4) (curve $F$ in Figure 2(a)) provides the degree of investment in followership $y$ for a given level of participation $c^{*}$ and leadership effort $i$. Together, these two relationships pin down the overall equilibrium to the model, and this point of intersection of the $P$ and $F$ curves is given by:

$$
\frac{(\alpha a)^{2} L_{1} \tau}{l G k}\left(c^{*}\right)^{2}\left(1-\frac{c^{*}}{c_{H}}\right)\left(1-\frac{c^{*}}{2 c_{H}}\right)=c^{*}\left(\frac{1}{p G \tau}-\frac{1}{c_{H}}\right)
$$

Solution(s) to this equation (if any) determine equilibria for the overall game. Clearly one possible equilibrium involves $c^{*}=0$. Here no one becomes a follower, the leader expends no effort and overall there is zero probability of change. However, there can be interior equilibria too.

Thus if the situation is as in case 1 of the figure, the only intersection is at $c^{*}=0$ and the only equilibrium for the game involves no change. On the other hand, in case 2 , there are two interior equilibria in addition to the status-quo equilibrium. To determine the precise condition for each 


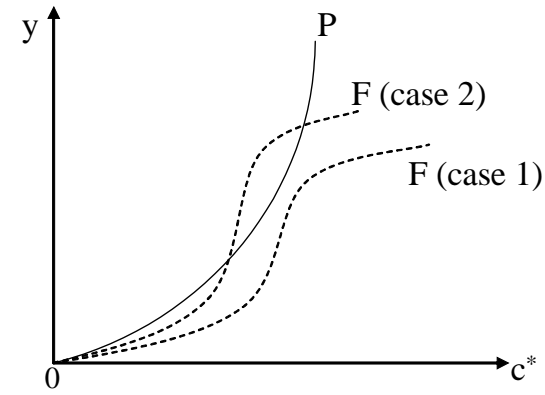

(a)

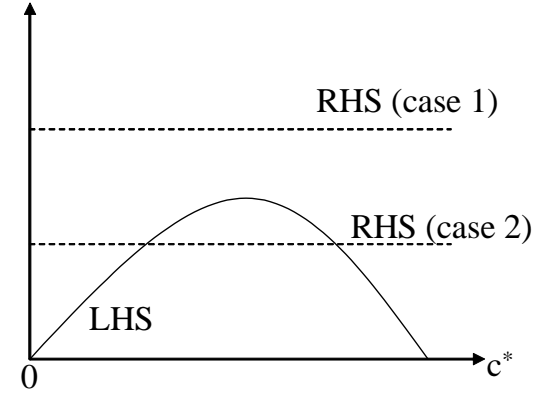

(b)

Figure 2: Overall equilibrium

case, one needs to take into account the relative speed of change of the two curves; equation (5) incorporates this. Eliminating a $c^{*}$ from both sides of the equation, the left-hand side is inverse U-shaped in $c^{*}$, as depicted in figure $2(\mathrm{~b})$, while the right hand side is a constant. Thus, depending on whether the right hand side lies above or below the highest point of the inverse U, there is either no interior equilibrium or two such. This is captured in the proposition below.

\section{Proposition 2 If}

$$
\frac{(\alpha a)^{2} L_{1} \tau c_{H}}{3 \sqrt{3} l k G}<\frac{1}{p G \tau}-\frac{1}{c_{H}}
$$

then the only equilibrium for the overall game is where no one becomes a follower i.e. $y=0$, and $i=0$ and there is no possibility of change. On the other hand, if this condition does not hold, then there are two interior equilibria in addition to the no action equilibrium.

\section{Proof. See Appendix.}

The above proposition demonstrates that the overall equilibrium to the game can be of two kinds. First, there always exists a degenerate status-quo equilibrium where there is no possibility of regime change. Under some circumstances, it is the only equilibrium. As condition (6) shows, this will be the case when the general prior $\alpha$ about the prospects for change is highly pessimistic, or the leader is of poor quality in terms of his ability at gathering information or communicating it, or when the perceived gains from change $G$ are relatively low. In all other circumstances, the above proposition points out the possibility of multiple interior equilibria. One is a high probability-of-change equilibrium involving a high level of followership $y$, a high degree of effort by the leader $i$, and overall a good amount of participation. At the same time, there also exists a low-level equilibrium with few becoming committed followers as well as less effort by the leader; in this case there is a relatively low (but non-zero) possibility of change. 
The multiple interior equilibria is the result of the interaction between the leader, the followers and the non-followers. As more people invest in becoming followers, thus committing themselves to taking action whenever called upon to do so by the leader, it increases incentives for the leader as well as increases participation by non-followers. Knowing that more people will act upon getting his message, the leader puts in more initiative at discovering the right conditions for change, thus raising the ex-ante chances of success. This encourages more people to invest in followership in the first place. It is the two-way feedback between followership, leadership and participation that thus leads to one equilibrium involving a high degree of all three and another with low degrees of all. Among the three equilibria (in case 2), the status quo equilibrium and the equilibrium with the highest level of $c^{*}$ are stable, while the middle one involving moderate levels of followership, participation and change is unstable. ${ }^{14}$ What are the implications of this proposition for leadership and how robust is the result? This is what we discuss next.

\subsubsection{Leadership, Change and Endogenous Threshold Effects}

A key implication of the above proposition is that it demonstrates the possibility of endogenous threshold effects for effective leadership. When condition (6) is not satisfied, no movement for change gets off the ground and there is no possibility of change. This is further illustrated in Figure 3(a): ${ }^{15,16}$ here, if the leader's ability is below an endogenous threshold (i.e. if $\tau$ or $1 / l$ is small enough), the probability of catalyzing change is zero. Above this threshold, the prospects for change increase discontinuously. This discontinuity is quite striking, given that all the underlying variables are continuous. It suggests that even though the leader here is exogenously given in the sense of being in a position to acquire and distribute pertinent information, not all leaders are able to get started a movement for change. Thus a distinction between leaders and effective leadership, the positive probability of bringing about change, emerges endogenously here. Looking at condition (6), change requires not only a leader of high enough ability, but also a combination of the right underlying conditions in the sense of an optimistic general outlook about the possibility and gains from change. Thus the view of leadership that emerges here conforms with what is popularly

\footnotetext{
${ }^{14}$ This can be seen from figure 2(a). At the middle equilibrium, consider a slight increase in $y$. From $(P)$, this translates into an increase in participation $c^{*}$, which feeds back into increased followership $y$ through the followership curve $(F)$. The resulting feedback is in fact greater than the initial increase in $y$, implying that the overall dynamics move away from this equilibrium. On the other hand, it is the opposite case for the status quo equilibrium and the equilibrium with the highest level of $c^{*}$ i.e. these two are stable.

${ }^{15}$ The figure is drawn under the assumption that the Pareto-dominant (and stable) equilibrium prevails i.e. the one with the highest $c^{*}$.

${ }^{16}$ As is clear from (6), a similar figure could also be drawn with any of the variables $\alpha, a, L_{1}, \tau, k$ or $G$ on the $\mathrm{X}$-axis.
} 


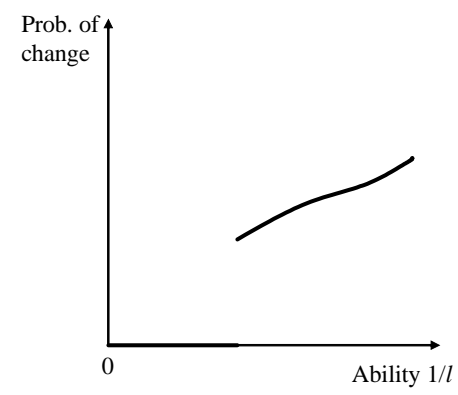

(a)

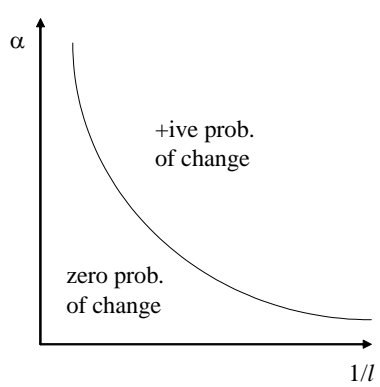

(b)

Figure 3: Effect on the probability of successful change

known as the "Weberian" view which stresses the importance of individual leader characteristics, but only under the right structural conditions. Figure 3(b) further highlights this interaction between the leader's ability $l$ and the public prior $\alpha$ in determining the chances for change. When the general outlook $\alpha$ is very optimistic, even leaders of low ability are able to catalyze change; on the other hand, in pessimistic times, the threshold ability level for effective leadership is much higher.

The mechanics underlying the threshold effects can be understood by looking at Figure 2(a). Consider the impact of a change in the leader's ability variable $l$. This has no effect on the $P$-curve since it represents the participation decision of non-followers which takes place after uncovering of the state by the leader. On the other hand, the $F$-curve represents ex-ante investment in followership. A lowering of $l$ implies increased initiative $i$ by the leader for any given level of participation $c^{*}$, and thereby encourages increased followership $y$. In other words, the $F$-curve shifts upward with a decrease in $l$, thus making (intersection and) interior equilibria more likely.

To see the intuition, we begin by observing that in the absence of a leader there is a coordination failure. By providing information, the leader helps resolve this coordination failure, but his effectiveness depends on the degree of underlying strategic complementarities. There are two channels through which strategic complementarities work in the model. First, is the complementarity that arises between followers and the participation decisions of non-followers. Second, the complementarity between the leader's ability and individual investment in followership. Accordingly, a leader of higher ability makes each individual's participation decision less dependent on the decisions of others - mitigating the coordination problem. Therefore, an increase in the leader's ability increases the size of committed followership. Moreover, this direct effect of a larger set of core followers further encourages participation by the non-followers. Together these two effects result in the leader's ability having a disproportionate impact on the probability of change. 
MacGregor Burns (1978) raised the difficulty in conceptually distinguishing between leadership and the leader's ability. The threshold effect result here suggests that the relationship between the two is highly non-linear and dependent on underlying conditions. A leader with ability even marginally below the threshold displays no leadership as compared to a leader with ability above the threshold.

\subsubsection{What Makes a Leader Effective? Perceptions or Reality}

Is the leader's effectiveness at transforming the status-quo a function of public perceptions or actual leader ability? Addressing this issue helps throw some light on the long-standing debate in leadership of whether change is driven by actual leader ability (the 'Great Man theory') or whether the underlying 'spirit of the times' was ripe for change. In addressing these questions we also examine the robustness of our results to allowing for a dispersion in beliefs in the population about underlying parameters, such as the leader's ability $l$ or the prospects for change, $\alpha .{ }^{17}$

In the model so far, we have assumed that all individuals share the same belief $\alpha$ about the possibility for change, about the congruence parameter $a$ and are perfectly aware of the leader's ability $l$. It can be argued that in reality individuals may differ in their perceptions about any or all of these parameters. As emphasized by Morris and Shin (2003) and others, it is more than likely that there is a heterogeneity in beliefs about underlying parameters. For instance, some individuals may be more optimistic than others about the leader's ability or the underlying conditions. Accordingly, in what follows we capture a possible heterogeneity in beliefs by focusing on dispersed perceptions about the leader's ability.

In particular, suppose the leader's ability $l$ is not known, but is commonly believed that this ability parameter is given by a random variable $\widetilde{l}$ which is distributed over the interval $[\underline{l}, \bar{l}]$ according to the $\operatorname{cdf} F(\widetilde{l})$, where $\bar{l}>\underline{l}>\alpha p \tau L_{s}$. Equivalently, one could assume that there is a dispersion in beliefs about the leader's ability, with $F(\widetilde{l})$ being the fraction of the population who believe the leader's ability to be below $\widetilde{l}$. The rest of the game is the same as before.

Uncertainty about $l$ does not affect the participation decision in the second period, as this decision is taken after the discovery of the state by the leader. Thus equation (1) still characterizes

\footnotetext{
${ }^{17}$ Our framework shares many features common to coordination games (e.g. Morris and Shin 2003). However, there are also important differences. First, our framework endogenizes the degree of complementarity by allowing individuals to invest in becoming "followers" prior to the leader's public signal. Second, the leader here is not a passive recepient of information that he makes public. Rather, he actively invests effort and resources in seeking and 'discovering' appropriate conditions for an attack on the status-quo. Together, these imply that for example, if a leader has no committed followers, then the public signal is ineffective in coordinating actions. On the flipside, if a leader has no committed followers, then he will not invest in change to begin with.
} 
participation of non-followers. Moving back to $T=1$, the effort decision $\widetilde{i}$ for a leader of ability $\widetilde{l}$ depends on the expected mass of participants $m^{e}$ in period $T=2$, and is given by a condition analogous to (2): $\widetilde{i}=\alpha \operatorname{apm}^{e} L_{1} / \widetilde{l}$.

At the initial period $T=0$, the followership decision of an individual is related to the expected effort that will be put in by the leader $E(\widetilde{i})$ and is given by ${ }^{18}: y=\alpha a \tau E(\widetilde{i})\left[c^{*}-\frac{\left(c^{*}\right)^{2}}{2 c_{H}}\right] / k$, which is analogous to equation (4). As before, incorporating $\widetilde{i}$ from the leader's decision and $y$ from the participation equation gives the overall equilibrium condition for $c^{*}$ as:

$$
\frac{(\alpha a)^{2} L_{1} \tau}{G k} E\left(\frac{1}{\widetilde{l}}\right)\left(c^{*}\right)^{2}\left(1-\frac{c^{*}}{c_{H}}\right)\left(1-\frac{c^{*}}{2 c_{H}}\right)=c^{*}\left(\frac{1}{p G \tau}-\frac{1}{c_{H}}\right)
$$

This is almost identical to equation (5) before, and therefore as in proposition 2 , the condition for whether or not the only equilibrium is the no action one is given by the condition:

$$
\frac{(\alpha a)^{2} L_{1} \tau c_{H}}{3 \sqrt{3} k G} E\left(\frac{1}{\widetilde{l}}\right) \lessgtr \frac{1}{p G \tau}-\frac{1}{c_{H}}
$$

Now observe that in the above condition, the leader's actual ability $l$ does not enter this inequality. This has a striking implication, in that it suggests that the threshold for effective leadership depends solely on the public perception about the leader's ability $E(1 / \widetilde{l})$. In other words, in the absence of a good reputation, even a high ability leader will be quite ineffective. However, once the threshold is crossed, the leader's actual ability plays a positive role in determining the prospect of change. In terms of figure 3(a), an increase in the leader's actual ability raises the non-zero part of the graph, but has no effect on the threshold at which the probability of change jumps discretely up. Therefore, our analysis suggests that a society's perceptions of a leader's ability are important because they influence the decision to become a follower. Gandhi's reputation (acquired in South Africa) was crucial in helping generate a cadre of committed followers when he arrived in India in 1915 and made him immediately effective.

Similarly, a dispersion in beliefs about the prospects for change, $\alpha$, can also be accommodated into the structure of the basic model. While individual beliefs $\widetilde{\alpha}$ affect followership decisions, the leader's personal belief $\alpha_{L}$ affects his leadership initiative $i$. Together, these result in an analogous overall equilibrium condition:

$$
\frac{a^{2} L_{1} \tau \alpha_{L} E(\widetilde{\alpha})}{l G k}\left(c^{*}\right)^{2}\left(1-\frac{c^{*}}{c_{H}}\right)\left(1-\frac{c^{*}}{2 c_{H}}\right)=c^{*}\left(\frac{1}{p G \tau}-\frac{1}{c_{H}}\right)
$$

where $E(\widetilde{\alpha})$ is the mean of the beliefs in the population. Again, as in proposition 2, if either $\alpha_{L}$ or $E(\widetilde{\alpha})$ is too small, then the only equilibrium involves persistence of the status quo. This

\footnotetext{
${ }^{18}$ In the case of dispersed beliefs, investment in followership by an individual who believes that the leader's ability is $\widetilde{l}$ is given by: $\widetilde{y}=\alpha a \tau \widetilde{i}\left[c^{*}-\frac{\left(c^{*}\right)^{2}}{2 c_{H}}\right] / k$. Now, integrating over the whole population, the total mass of followers is given by $y=\alpha a \tau E(\widetilde{i})\left[c^{*}-\frac{\left(c^{*}\right)^{2}}{2 c_{H}}\right] / k$.
} 
result has interesting implications. It suggests that the prevailing zeitgeist directly impinges on the prospects of change. If expectations for change were sufficiently optimistic, even a leader of relatively modest talents can bring about revolution. For instance, Lenin's return to Petrograd in April 1917 was so effective, because the prospects for a successful revolution were believed to be high. This is not to deny the possibility that Lenin was a leader of high ability and his role in the October Revolution was key (see Service, 2000 for a discussion). Rather it is to emphasize that most cases of change occur due to some combination of the expectations about underlying prospects of change and the leader's reputation. Indeed it is precisely this possibility that has perhaps contributed to the diverse viewpoints among social scientists regarding the importance of the leader's inherent ability versus the underlying public belief in contributing to change.

We summarize the above argument that both expectations as well as fundamentals matter for the exercise of effective leadership in the following proposition.

Proposition 3 The population's perception of the leader's ability $E(1 / \widetilde{l})$ or of the prospects for change $E(\widetilde{\alpha})$ determines the threshold for effective leadership where there is a positive probability of change. However, once this threshold is crossed, the leader's actual ability helps determine the overall probability of change.

\subsubsection{Leadership and Threshold Effects: the Role of Complementarity}

How does the degree of complementarity in individual participation decisions matter for the equilibrium and therefore for the overall probability of successful change? In addressing this question

we revert to the general formulation, where the probability of change is given by $\frac{1}{\theta} p m^{\theta}$, with $\theta>0$. Recall that the parameter $\theta$ now captures the degree of complementarity in the process, as a smaller $\theta$ corresponds to a higher marginal product of increased participation $m$. The structure of the game is the same as before except that (similar to Assumption 2), we now assume:

Assumption $2^{\prime}: p \tau G<\theta c_{H}$

The analysis of the participation decision, the degree of leadership effort exerted and the investment into followership is very similar to that above and are derived in the Appendix. Together, the overall equilibrium condition for $c^{*}$ is now given by the equation:

$$
\frac{(\alpha a)^{2} L_{1} \tau}{l G k}\left(c^{*}\right)^{2}\left(1-\frac{c^{*}}{c_{H}}\right)\left(1-\frac{c^{*}}{2 c_{H}}\right)=c^{*}\left(\left(\frac{\theta}{p G \tau}\right)^{\frac{1}{\theta}}\left(c^{*}\right)^{\frac{1}{\theta}-1}-\frac{1}{c_{H}}\right)
$$

Clearly $c^{*}=0$ (i.e. one where no one becomes a follower, the leader expends no effort and overall there is zero probability of change), is an equilibrium now too. Looking for interior equilibria, the left hand side of (7) is the same as that of (5). However the right-hand side is now different and 
the interior equilibria in some cases will now be unique and may involve no threshold requirements for leaders to be effective. The following Corollary to Proposition 2 analyzes this in more detail.

Corollary 1 For $\theta<1$, in addition to the status-quo equilibrium, there always exists an interior equilibrium with a positive probability of change. For $\theta \geq 1$, there are threshold effects since there exists a range of parameters under which the status-quo is the only equilibrium.

Proof. See Appendix.

This proposition shows that when $\theta$ is low, there always exists an interior equilibrium. This implies that there are no threshold effects in leadership when $\theta$ is less than 1 . In other words, over the entire range of leadership ability $l$ or $\tau$, small changes in the leader's ability or in any of the underlying parameters result only in a small change in the probability of successful change. On the other hand, when strategic complementarity is high i.e. for any $\theta \geq 1$, there exists thresholds similar to condition (6) that must be satisfied for a leader to be effective.

The underlying intuition for this difference stems again from the strategic complementarity between committed followers, non-followers and the leader. When $\theta<1$, slight increases in the number of followers (at $y=0$ ) results in a big increase in the participation of non-followers, thus overall leading to a substantial increase in the mass of participants. Together this implies that a small increase in followership also results in a significant improvement to the leader's incentive in light of the expected change in overall participation. On the other hand when $\theta \geq 1$, a marginal increase in $y$ (at $y=0$ ) results in only a small marginal increase in the overall number of participants and thus is not enough to spur the leader into putting in more effort. In this case only a leader of sufficiently high ability helps resolve the coordination failure by making successful outcome to each individual's investment much less dependent on the actions of others. Thus, when $\theta \geq 1$, there exist threshold effects in catalyzing change.

\subsection{Leaders and Followers under Imperfectly Congruent Preferences}

The analysis above was for a "benevolent" leader i.e. one whose preferences for change are perfectly aligned with that of the majority. While this may be true in some instances, it need not always be the case and the leader may have his or her own agenda for change separate from that desired by the majority. We now explore this possibility.

When the leader's interests are known to be aligned with a particular group, individuals in this group do not have much reason to suspect his motives when he issues a call for action. However, if the leader belongs to a different class, ethnicity or religious group whose preferences for change are divergent, the individual response may be rather different. For instance, a Shiite leader's call 
to arms with the aim of overthrowing Saddam Hussein in Iraq may be viewed quite differently by a Sunni than a Shiite. Accordingly, we now analyze the case where the leader may belong to or have interests aligned with group $E$ and thus his preferences for change may diverge from that of the majority group $M$. In doing so, it also allows us to discuss in the same framework instances of "good" as well as "bad" changes i.e. changes in which gains accrue to only a narrow minority while all bear the cost.

We assume that the leader's initial reputation of being benevolent i.e. having preferences congruent with group $M$ is given by $\lambda \in(0,1)$. Recall that in state $G_{0}$, only participants from group $E$ gain; those from group $M$ gain nothing but incur the cost of participation $c$. The ex-ante prior on the state being $B$ is given by $1-\alpha$, while that on it being $G_{1}$ is $\alpha a$ and on it being $G_{0}$ is $\alpha(1-a)$. A higher $a$ implies a greater coincidence of objectives between the two groups and thus also between a group $E$ leader and the majority.

For a leader whose interests are aligned with group $E$ we assume $L_{1}>0$ as well as $L_{0}>0$, so that it is optimal for him to issue a call for action in state $G_{1}$ as well as in $G_{0} \cdot{ }^{19,20}$ Thus upon receiving a message from the leader, people in group $M$ are no longer sure about its credibility, and their updated probability about the state being $G_{1}$ is given by:

$$
\operatorname{Prob}\left(G_{1} \mid \text { message }\right)=\widehat{a}=\frac{a}{a+(1-\lambda)(1-a)}
$$

As expected this is increasing in $\lambda$, the probability that the leader is of the benevolent type. While all committed followers participate (as their cost of doing so is 0 ), among the non-followers only those with low enough costs do so. This cutoff cost $c^{*}$ is now given by:

$$
c^{*}=\widehat{a} p \tau\left[y+(1-y) \frac{c^{*}}{c_{H}}\right] G
$$

As $\lambda$ increases, $\widehat{a}$ increases, and this equation implies that as a result $c^{*}$ also rises. In other words, an increase in $\lambda$ raises credibility of the leader and thus results in greater participation by the populace. Thus greater credibility raises the prospect of change by encouraging more mass participation — this we call the "credibility effect".

However, our framework highlights that there is an additional aspect of a leader who does not belong to group $M$. As pointed out above, if it was personally advantageous, such a leader

\footnotetext{
${ }^{19}$ Instead of group alignment, one could also think of state $G_{1}$ as one in which change is personally beneficial for the leader (e.g. consolidates his hold on power) without bringing any widespread benefits.

${ }^{20}$ While the leader's message here has been assumed to only involve a call for action or not, enriching it in the sense of allowing the leader to also declare the state of the world as $G_{1}$ or $G_{0}$ would not change the analysis. The benevolent leader would declare the state truthfully while the self-interested leader would identify both states $G_{1}$ and $G_{0}$ as being $G_{1}$. Thus the inference problem for the population would be the same as here.
} 
would be willing to be unscrupulous and would not hesitate to encourage the populace to make an inefficient investment in overturning the status quo. Somewhat unexpectedly, the political ambitions of such a leader can have beneficial consequences too. This willingness to leave no stone unturned in order to acquire political power makes it more likely that such a leader may also (on occasion) unearth a socially optimal window of opportunity for change (i.e. in state $G_{1}$ ). To see this, consider first a benevolent leader. This leader calls for action and gains only in the state $G_{1}$; thus, taking the expected mass of participants $m^{e}$ as given, a benevolent leader's optimization problem is given by: $\max _{i_{b}} \alpha a i_{b} p m^{e} L_{1}-e\left(i_{b}\right)$ with the associated first-order condition:

$$
\operatorname{\alpha apm}^{e} L_{1}=l i_{b}
$$

For the politically ambitious leader the gains come about both in states $G_{1}$ and $G_{0}$ and thus the first-order condition characterizing his effort $i_{s}$ is given by:

$$
\alpha p m^{e}\left(a L_{1}+(1-a) L_{0}\right)=l i_{s}
$$

Comparing the two we see that $i_{s}=\left(1+\frac{1-a}{a} \frac{L_{0}}{L_{1}}\right) i_{b}$. The ambitious self-interested leader benefits politically from change in both states $G_{0}$ and $G_{1}$, with the unintended social benefit of (potentially) also acquiring more information in state $G_{1}$. This sets up the basic trade-off here: while a benevolent leader is more credible and elicits wider mass participation in response to his message (the 'credibility effect'), a politically ambitious leader may acquire more information - the 'ambition effect'. We next examine how the two effects compare.

For simplicity in exposition, we assume $L_{0}=L_{1}=L$, thus implying $i_{b}=a i_{s}$. From an ex-ante perspective, the probability of successful change occurring in state $G_{1}$ (under a leader who is benevolent with probability $\lambda$ ) is given by:

$$
P_{1}=\lambda i_{b} p m^{e}+(1-\lambda) i_{s} p m^{e}=\frac{\alpha p^{2} \tau^{2} L}{l}(\lambda a+1-\lambda)\left[y+(1-y) \frac{c^{*}}{c_{H}}\right]^{2}
$$

where in equilibrium the expected mass of people participating is given by $m^{e}=\tau\left[y+(1-y) \frac{c^{*}}{c_{H}}\right]$. $P_{1}$ encompasses the two above-mentioned effects at work: as $\lambda$ rises, the expected effort put in by the leader (proportional to $\lambda a+1-\lambda$ ) falls, while due to increased credibility, participation conditional on receiving a message, $\left[y+(1-y) \frac{c^{*}}{c_{H}}\right]$, rises. The following proposition derives the overall impact of $\lambda$ on the probability of successful change in state $G_{1}$.

Proposition 4 For $\widehat{a}<\frac{c_{H}}{3(1-y) p G \tau}, P_{1}$ is decreasing in $\lambda$, while for $\widehat{a}>\frac{c_{H}}{3(1-y) p G \tau}, P_{1}$ is increasing in $\lambda$.

Proof. See Appendix. 


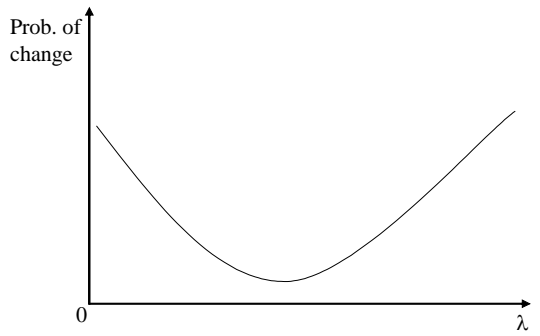

Figure 4: Effect of $\lambda$ on the probability of change in state $G_{1}$

The above proposition establishes that the leader's type has a non-monotonic effect on the probability of bringing about change in the state $G_{1}$ where everyone benefits from it. For low values of $\lambda$, the effect of an increase in $\lambda$ is to lower the probability of change, while beyond a certain point, this effect is positive. This is depicted in figure 4. The U-shaped relationship emerges due to the trade-off between the "credibility" and "ambition" effects. A greater alignment of the leader's preferences $\lambda$ with those of the populace has two possible effects on $P_{1}$. First, an increase in $\lambda$ has a positive impact on $P_{1}$ due to the greater credibility of such a leader. At the same time, it has a negative impact on the leader's 'ambition' effect. Which dominates? Note that credibility is a more important factor in the participation decision of non-followers as they stand to lose more by participating (mistakenly) in state $G_{0}$. When $\lambda$ is low, the leader's credibility is low and not many non-followers participate in any case. Thus in this case, the positive credibility effect due to an increased $\lambda$ impacts only a small group. In contrast, due to the adverse impact on the leader's initiative, the same increase in $\lambda$ has a negative effect on followers and non-followers alike. Therefore, when $\lambda$ is small, the overall effect of an increase in $\lambda$ is to lower the probability of change. ${ }^{21}$ The opposite holds for larger values of $\lambda$. In this case, there is bigger participation by non-followers to begin with, and thus the positive credibility effect is the dominant effect at work.

The above analysis is of course contingent on a given level of followership $y$ and shows that a higher ex-ante probability of the leader being a benevolent type need not always translate into a greater probability of change even in the state where everyone benefits from it. The analysis shows in a sharp way that a self-interested leader driven by ambition can be a strong force for change. This idea resonates well with Caro's (2002) sketch of Lyndon Johnson, where he argues

\footnotetext{
${ }^{21}$ It is also interesting to note the impact of an increase in the number of followers $y$ on the turning point in the above graph, i.e. $\lambda=c_{H} /[3(1-y) p G \tau]$. As $y$ increases, this turning point increases. In other words, as the number of followers rises, the effect of increased $\lambda$ is negative over a bigger range. The reason is that the leader's credibility is not a concern for followers since their participation cost is zero to begin with. For them, the main effect is due to the effort put in by the leader. An increase in $\lambda$ lowers effort and thus reduces the possibility of change.
} 
that Johnson was effective in pushing through the Voting Rights Act because there was a political imperative for him to do so. According to Caro, Johnson's relentless pursuit of the Presidency propelled him to acquire information about the possibility (and the political benefits) of pushing through civil rights legislation. Indeed, Johnson worked very hard at persuading fellow senators to follow his recommendation and vote for civil rights.

Endogenous Followership: We now consider the effect of the leader's type on followership and consequently on the overall chances of change. Section 3.1 dealt with the case where the leader is a benevolent type. For comparison, we now consider the diametric opposite case where the leader is known to be of the self-interested type i.e. $\lambda=0$.

In this case, $\widehat{a}=a$ and the marginal participant is given by: $c^{*}=a p \tau\left[y+(1-y) \frac{c^{*}}{c_{H}}\right] G$ and the effort put in by the leader is: $i_{s}=\frac{\alpha}{a l} \frac{L}{G} c^{*}$.

To evaluate the value of followership for an individual from group $M$, one needs to calculate the date $T=2$ expected gains in states $G_{0}$ and $G_{1}$. In either state, provided the leader uncovers it and one receives the leader's message, one will participate if either one's cost is 0 (which happens with probability $y$ ) or it is below $c^{*}$. Thus in state $G_{x}, x \in\{0,1\}$, the expected future gains are:

$$
i_{s} \tau\left[y V_{x}+(1-y) \int_{0}^{c^{*}}\left(V_{x}-c\right) \frac{d c}{c_{H}}\right]
$$

where $V_{x}$ is the expected gain to participating in state $G_{x}$ and is given by $V=0$ in state $G_{0}$ and $V=p \tau\left[y^{e}+\left(1-y^{e}\right) \frac{c^{*}}{c_{H}}\right] G=\frac{c^{*}}{a}$ in state $G_{1}$. Combining the two payoffs gives the overall value of followership $y$ :

$$
i_{s} \tau\left[\alpha a\left\{y \frac{c^{*}}{a}+(1-y) \frac{\left(c^{*}\right)^{2}}{c_{H}}\left(\frac{1}{a}-\frac{1}{2}\right)\right\}-\alpha(1-a)(1-y) \frac{\left(c^{*}\right)^{2}}{2 c_{H}}\right]
$$

Compared with the case of a benevolent leader, there is an added incentive for followership here, namely the alignment of one's interests with those of the leader. This is important in the state $G_{0}$; being a follower participant in this state incurs zero loss as one's cost of participation then is 0 . Being a non-follower participant however, one incurs the positive costs of participation $c$, without getting any benefit. Investing in followership thus provides insulation by reducing the expected loss in this situation. While we have cast followership in the model in terms of a lower cost of participation, it could analogously be modeled as investing in higher gains from change. Again, the incentive for a follower would be to align one's interests more closely with those of the leader (or his group) so as to reap greater gains under all circumstances. For example, this could be by adopting a technology or an occupation that is closer in line with that of the elite group $E$ so as to achieve gains in both states $G_{1}$ as well as $G_{0}$. 
Weighing the marginal gain from increased investment in followership y against its marginal cost $f^{\prime}(y)$, one gets the condition for the optimal degree of followership here:

$$
\alpha i_{s} \tau\left[a\left\{\frac{c^{*}}{a}-\frac{\left(c^{*}\right)^{2}}{2 c_{H}}\left(\frac{2}{a}-1\right)\right\}+(1-a) \frac{\left(c^{*}\right)^{2}}{2 c_{H}}\right]=k y
$$

The second term within square brackets on the left-hand side captures the added incentive to become a follower here due to the insulation effect of followership. As before, incorporating $y$ from (8), and rearranging terms, one gets the overall equilibrium condition:

$$
\frac{\alpha^{2} L \tau}{l G k}\left(c^{*}\right)^{2}\left(1-\frac{c^{*}}{c_{H}}\right)\left(1-\frac{c^{*}}{2 c_{H}}\right)=c^{*}\left(\frac{1}{p G \tau}-\frac{a}{c_{H}}\right)
$$

This expression is similar to the equilibrium condition for a benevolent leader (5). Thus the equilibrium structure here is the same as before and again involves threshold effects in the probability of bringing about change. Since the model here endogenously develops a notion of effective leadership in terms of what is the threshold level of ability required to catalyze change, one can thus compare the level of effectiveness of a benevolent versus a self-interested leader in terms of these thresholds. The following proposition makes this comparison.

Proposition 5 If $c_{H}>\frac{3}{2} p G \tau$, then for all a, the threshold level of ability $l$ that is required for a benevolent leader to be effective is higher than that for a self-interested leader. If $c_{H}<\frac{3}{2} p G \tau$, then there exists a cutoff level $a^{*}$ such that for $a<a^{*}$, a benevolent leader needs to satisfy a higher threshold ability level to demonstrate effective leadership. In contrast, for $a>a^{*}$, the threshold ability level required for effective leadership is higher for a self-interested ambitious leader.

Proof. See Appendix.

What kind of leader is more effective at transforming the status-quo - a benevolent or an ambitious one? In terms of the minimum ability level required for effective leadership, the above proposition highlights that the answer depends on the expected participation costs (given by $c_{H} / 2$ ) and the degree of congruence between the two groups (given by $a$ ). The key to the intuition here is that as discussed before, when the level of followers is high, a self-interested leader is more likely to bring about change as compared to a benevolent one. The above proposition identifies two conditions under which individuals have a greater incentive to become followers. First, when $c_{H}$ is high, the expected cost of participation ex-post is high, and therefore the desire to reduce participation costs in the future provides a strong ex-ante incentive to invest in followership. Second, when the relative probability of state $G_{1}$ is low (i.e. $a$ is small), an individual from group $M$ has a greater incentive to become a follower in order to insulate himself from the prospect of adverse change. Under both these circumstances (i.e. a high $c_{H}$ and/or a low $a$ ), individuals' 
incentive to invest in followership is high. Thus in these cases, the threshold ability level required for effective leadership is lower for the self-interested leader.

Note that while the potential for effective leadership is higher for a self-interested leader in certain circumstances, such a leader is also more likely to enact change that is costly for all but benefits only a narrow minority. Thus a natural question is: for a given level of leader ability $l$, what kind of leader is preferred by each group? In other words, in ex-ante welfare terms can it be that a self-interested leader may be preferred by the majority to a benevolent one? This is addressed in the next proposition. Of course, given multiple interior equilibria, in making welfare comparisons, the choice of equilibria is important. In all cases, we consider the Pareto-dominant one i.e. the one with the highest $c^{*}$.

Proposition 6 If $c_{H}>\frac{3}{2} p G \tau$, the ex-ante welfare in the Pareto-dominant interior equilibrium (if it exists) under a self-interested leader is higher than that under a benevolent leader of the same ability. If $c_{H}<\frac{3}{2} p G \tau$, then the above is true for small values of a.

Proof. See Appendix.

This proposition shows that in terms of ex-ante welfare, there is a broad range of parameters under which a self-interested leader would be preferred not only by the elite group $E$ but also by the majority $M$ with whom it is known that the leader's interests do not always coincide. Thus even if one were to consider the issue of leader selection at the beginning of the game, it is possible that the majority may wish to select a leader with objectives not always congruent with theirs.

The intuition for the above result can be understood by first observing that for a given level of participation $c^{*}$, a self-interested leader is always preferred by the populace. This is because such a leader is viewed as more likely to acquire information about whether a window of opportunity for change exists - the "ambition effect". So the issue is how does the leader's preferences affect the overall level of participation $c^{*}$ ? There are two opposing considerations at work. First, a self-interested leader's lack of credibility tends to lower overall participation. On the other hand, the desire to align interests means that an ambitious leader may have a larger number of followers (the insulation effect) - this tends to drive up $c^{*}$. As in proposition 5, the insulation effect (and thus followership) is likely to be strongest when the expected costs of participation $\left(c_{H} / 2\right)$ is high as well as when the relative probability of the good state, $a$, is low. In these cases, the insulation effect dominates the credibility effect, and $c^{*}$ is high. In this case individuals prefer an ambitious self-interested leader to a benevolent one from their own group.

The above proposition suggests why individuals may willingly choose to follow leaders such as Hitler, Lenin or Mugabe. Our analysis shows that there are two reasons as to why individuals may become members of the ZANU-PF party in Zimbabwe, the Baath Party in Iraq or indeed even 
the Nazi party in Germany. The first is the perception that (probabilistically) these ambitious leaders can be effective and are likely to catalyze a transition that may result in direct rewards for all followers. However as discussed above, individuals also have an incentive to become followers in order to insulate themselves against adverse change - the "insulation effect". This aspect of followership is described (in the Nazi case) by Thyssen (1941), Brustein (1996) and Kater (1983) and by Kravchenko (1947) (in the Soviet case), who document how (among other motivations) prudent self-insurance was an additional consideration driving individuals to become members of the Nazi (or Communist) party when Hitler (respectively, Stalin) came to power. Individuals may become followers of leaders they know to be mendacious in an attempt to insulate themselves from the adverse impact of any changes that may occur under the aegis of such leaders.

\section{Leadership in Different Environments: A Discussion}

\section{Political Institutions and the Scope of Leadership}

Does the exercise of leadership differ across the nature of political regimes? We address this question by focusing on the fact that democratic political institutions help screen across leaders in a way that is impossible in an autocracy. In particular, democratic elections ensure that the leader's preferences are (on average) likely to be closer to that of the majority. Here we discuss the implications on the exercise of leadership of greater congruence of preferences between the populace and the leader.

On one hand, an autocratic leader is much less institutionally constrained and can more easily bring about certain kinds of changes through the issue of an edict or decree. However for an autocrat, achieving the voluntary and enthusiastic participation of the populace to invest in reform and large scale change is difficult. In part, this is because such a leader is more likely to be perceived as having preferences aligned with that of the elite or the 'selectorate' (see Besley and Kudamatsu, 2007) rather than with the masses. In terms of the present model, leaders in autocracies are more likely to have preferences aligned to the elite (i.e. $\lambda \rightarrow 0$ ) while leaders in democratic societies are more likely to have preferences aligned with the majority ( $\lambda$ closer to 1 ). From Proposition 4 , for changes involving a high degree of congruence (i.e. $a>a^{*}$ ), the ability threshold for effective leadership is stricter for a self-interested (i.e. $\lambda=0$ ) leader. In other words, taking the same ability distribution of leaders across different political regimes, we are more likely to see changes perceived as yielding all-round gains being attempted in democracies. In contrast, when there is a low degree of congruence between the leader and the populace (i.e. for $a<a^{*}$ ); changes with a mismatch of interests between the majority and the elite have a greater likelihood of being attempted in autocracies. Indeed this accords well with the contrasting experience of the type 
(and frequency) of economic reforms attempted in autocracies such as China and Singapore versus those attempted (or not) in democratic India.

In terms of outcomes, majority aligned $(\lambda=1)$ leaders only attempt changes in state $G_{1}$ where it is in the majority's (and elite's) interest. On the other hand, elite-biased $(\lambda=0)$ leaders attempt changes in both states $G_{1}$ and $G_{0}$. Note that in the latter state, even if the change is successful, only the elite gain from it. Thus, given that autocracies are more likely to have leaders with $\lambda$ close to 0 , this implies that there is likely to be greater variance in outcomes in autocracies as against democracies. This accords well with the findings of Jones and Olken (2006) and Besley and Kudamatsu (2007) that the variance in economic outcomes and institutional change is much higher in autocracies than in well functioning democracies.

Media Freedom and the Exercise of Leadership:

The existence of media freedom is a distinctive aspect of modern democracies. Independent, critical reporting is much more difficult in countries where civil liberties are lacking and political institutions tend to be autocratic. Here we discuss the implications of an independent and free media on the exercise of leadership.

We introduce the idea of an independent and free press in a simple way. In particular, we assume that there exists a separate agent, whom we call the 'media', who can independently verify the leader's call for action. Accordingly, we assume that if the leader calls for action in the state $G_{0}$, then with probability $n$ the media learns of the true underlying state and reveals it to the public. Thus, by constraining the leader's attempts to pursue changes that benefit only the elite, the media here acts as a watchdog. For the discussion that follows, we assume that $n>0$ in a democracy, while in an autocracy the media does not have a 'watchdog' role, i.e. $n=0$.

Consider a leader with reputation $\lambda$. If this leader issues a call for action and is not contradicted by the media, then people's updated probability about the state being $G_{1}$ is given by:

$$
\operatorname{Prob}\left(G_{1} \mid \text { msg., silent media }\right)=\widehat{\widehat{a}}=\frac{\widehat{a}}{\widehat{a}+(1-n)(1-\widehat{a})}
$$

Observe that this expression is increasing in $n$. In other words, in the presence of an independent media, a leader's call for change has greater credibility with the population. Accordingly, the cutoff participation cost $c^{*}$ for non-followers is now given by: $c^{*}=\widehat{\hat{a}} p \tau\left[y+(1-y) \frac{c^{*}}{c_{H}}\right] G$. As $n$ increases, $\widehat{\widehat{a}}$ increases, resulting in greater mass participation.

At the same time a free press constrains a self-interested ambitious leader's incentive to call for investment when the state is $G_{0}$. Indeed, greater press freedom (high $n$ ) also lowers his incentive to discover information about the underlying state. ${ }^{22}$ Thus an increase in press freedom (higher

\footnotetext{
${ }^{22}$ This can be seen from the first-order condition for the optimization problem now: $l i_{s}=\alpha[a+(1-a)(1-n)] p m^{e} L$.
} 
$n$ ) sets up the basic trade-off here: while a freer media makes the leader more credible (similar to the "credibility effect" before) and elicits more response to his message, it lowers initiative put in by a self-interested leader (the "ambition effect"). In comparison, a benevolent leader's effort is given by: $i_{b}=\frac{a}{a+(1-a)(1-n)} i_{s}$. Thus as $n$ approaches 1 , both benevolent and self-interested leaders' actions become similar. Therefore, a democracy with an independent media constrains leaders.

We now examine the impact of greater press freedom, on the ability of the leader to bring about change. The probability of change in the ' good' state $G_{1}$ for a given mass of followers is:

$$
P_{1}=\left[\lambda i_{b}+(1-\lambda) i_{s}\right] p m^{e}=\alpha \frac{L}{G^{2} l}\{a+(1-a)(1-n)\}\left(\frac{c^{*}}{\widehat{\widehat{a}}}\right)^{2}
$$

This expression captures the two effects at work due to increased media vigilance. The negative 'ambition effect' is captured by term in the curly brackets while the credibility effect that increases participation is given by $\left(\frac{c^{*}}{\widehat{a}}\right)^{2}$. For regimes with an already reasonably independent media (i.e. a high $n$ ), a further increase in independence can only improve the prospects for change. In contrast, in a regime with poorly functioning media, the effect is reversed. However, the media also constrains the possibility of (harmful) change in the state $G_{0}$. Here in addition to the above two effects, there is the direct vigilance effect of a more active media. This probability is given by $P_{0}=(1-n)(1-\lambda) i_{s} p m^{e}$. An increase in $n$ now has the additional direct effect of lowering $P_{0}$ through the term $(1-n)$. Thus the positive participation effect of an increased $n$ can be much dampened by this direct vigilance effect and may serve to overall lower the probability of such harmful change occurring.

Greater press freedom usually accompanies democratization of political institutions. However, our analysis suggests that the relationship between greater press freedom and the leader's effectiveness at catalyzing change is not straightforward. In particular, we demonstrate that the relationship is non-monotonic, with a more independent media improving the possibility of change, but only if it was moderately independent to begin with.

\section{Leadership and Change: Examples in Three Contexts}

In this section we describe a few examples in a variety of contexts which illustrate some of the key elements of our framework. Namely, (a) the leader's ability to rally and coordinate individual investment decisions through the identification of suitable windows of opportunity as well as effective communication, and (b) the feedback relationship between leadership and followership: a leader with a high reputation attracts followers, who in turn make the leader more effective. 


\section{Social and Environmental Reform Movements}

Our framework applies to the role of leaders in catalyzing social change of various kinds, from the elimination of racial, gender and caste discrimination, the temperance movement, the campaign to ban child labor and also to environmental movements. ${ }^{23}$ We now describe in some detail Gandhi's attempt at social change.

Gandhi and Untouchability in the Indian Caste System. One of the longest surviving social institutions found anywhere is that of the caste system in India. A particularly pernicious aspect of the system is the practice of 'untouchability'. Some individuals are designated as 'untouchables' and all others are prohibited from social interaction with these 'untouchables' who are only allowed to hold scavenging jobs. Social interaction is strongly governed by the caste code, where any one who interacts with an 'untouchable' becomes a social outcaste and untouchable himself.

Gandhi had strong convictions and viewed the elimination of untouchability as a very important issue early on. While in his personal life he embraced untouchables, Gandhi realized that education and his personal example alone was not going to be sufficient to transform the age-old social institution. Gandhi's decision to spend most of his time living in and interacting with village India gave him prolonged exposure and a much better understanding of the pulse of the country, local traditions and the issues they felt strongly about. Gandhi's decades in village India correspond to a high investment $i$ in our model. Accordingly, Gandhi was patient and waited for the apposite window of opportunity to appear. During this time, through his struggle against the British and his fight against landlords and other social evils, Gandhi's reputation increased as did the number of his committed followers in and outside the Congress Party (a higher $y$ ).

When the British proposed to have separate electorates for the untouchables, Gandhi immediately perceived that this was the right moment to strike (i.e. a state corresponding to $G_{1}$ ) - since not only did he now have a large number of committed followers, but also because he could obtain broad support by fusing a fight against untouchability with a fight against British rule. Gandhi also showed his communication ability $\tau$, since he was aware that the best way for him to communicate the intensity of his feelings was through going on a fast unto death in protest against both British rule and untouchability. According to Willmer (1984) this resulted in "......events that astounded all who knew of the almost automatic loathing and fear felt by caste Hindus at the very thought of being touched by or in close proximity to an Untouchable....... Even more astonishing was the public fraternization of Hindus with Untouchables. In the streets of the

\footnotetext{
${ }^{23}$ For instance, the success of the 'tree woman' Wangari Maathai and her Green Belt movement in Kenya owed much to her ability to mobilize thousands of women followers. Similarly, the success of the Chipko Andolan (Hug the Trees) movement to prevent deforestation of the Indian Himalayas was attributable to the ability of its two leaders, S. Bahuguna and C.P. Bhatt, and the large number of committed followers.
} 
cities, high caste Hindus were seen eating together with the cobblers, street cleaners, sweepers and scavengers......Gandhi had produced a miracle. The long tradition of acceptance and approval of untouchability was shattered and the basis was laid for its ultimate disappearance."

In an era where there was almost no mass media such as radio and television and most of the population was illiterate, this quick mobilization of support for eliminating untouchability was partly possible due to Gandhi's seizing of the right moment and partly due to the legion of committed followers that Gandhi had (Amin, 1984). The above episode dramatically illustrates the symbiotic relationship between Gandhi and his followers that made him so effective.

\section{Political Transitions}

Leaders have often been crucial to catalyzing changes in political institutions. Examples range from Lenin's role in the October revolution, to Lech Walensa in leading the Solidarity movement to overthrow the status-quo in Poland or legislative and constitutional changes that expanded the scope of voting rights (as in South Africa and the United States). Here we illustrate the applicability of our framework using one of the best documented cases of institutional change within a well-functioning democracy.

Lyndon Johnson and the Voting Rights Act. ${ }^{24}$ For eighty two years prior to 1957 no civil rights bill for blacks had successfully managed to pass through the United States Senate due to opposition by a bloc of Southern senators. Despite many attempts, there seemed to be no common ground between the pro and anti civil rights forces and "the chasm between the two sides was unbridgeable" (Caro 2002, p. 948).

To being with, by this time Lyndon Johnson (LBJ) had already built up reputation as a powerful Majority leader of the Senate. As Caro documents (pp. 562-65), Johnson had the committed support of the "Big Bulls" of the Democratic Party in addition to his sizable "first team" of followers in the Senate. ${ }^{25}$ The loyalty that he commanded made Johnson a formidable force. However, having a large base of followers $y$ was not enough - he needed a window of opportunity. Motivated doubtless by his presidential ambitions, LBJ spent an enormous amount of time (high $i$ ) and resources trying to figure out the requirements, weaknesses and strengths of all parties necessary to the striking of a deal. LBJ's leadership skill lay in being the first to 'discover' a window of opportunity for an agreement in the form of a mutually advantageous

\footnotetext{
${ }^{24}$ For most of what follows we extensively draw on Robert Caro's (2002) masterly biography of Lyndon Johnson; all page citations refer to that book.

${ }^{25}$ Individuals who were not on LBJ's 'first team' of committed supporters, found that the price of getting in his good books was an explicit price in the form of favors to be done, before they could expect any benefits. (see Caro's discussion on 'The Johnson Rule'). This corresponds directly with the up-front cost $y$ that an individual invests in in order to become a follower in our model.
} 
deal between two key factions in the Senate: the Southern Senators who cared about civil rights legislation and the senators from the mountain states who wanted a hydro-electric project at Hells Canyon. According to Caro, Johnson was skilled enough to see "a potential connection between the two realities. No one else had seen it. During the ten years that Hells Canyon had been before Congress, there had not been the slightest link between the dam and civil rights". As a result of his skill (small $l$ ), and high investment $i$ in identifying a 'window of opportunity' and aided by his sizable 'first team' of followers (high y), Johnson made history. He managed to persuade enough senators on both sides to compromise, such that on August 7, 1957 the path-breaking Voting Rights bill was finally approved. It was hailed by the New York Times as "incomparably the most significant domestic action of any Congress in the twentieth century."

\section{Economic Reform and Organizational Transformation}

Our framework also applies to the role that individual leaders have had in catalyzing changes in the economic sphere, be it within the context of a firm or economy-wide. Although incentive contracts are common in firms, there is also a voluntary component to the relationship between the CEO and his employees. As Kotter (2002) emphasizes, these non-contractible aspects of employee decision making assume particular importance during attempts to implement changes in the organizational philosophy and outlook. A classic example is Jack Welch's role at General Electric (GE). He took a key role in catalyzing organizational transformation by facilitating coordinated (costly) investment by the firm's employees - from retraining, acceptance of new management practices to buying into a new organizational philosophy. When he took over as CEO of GE, Welch was quick to put his followers (called his "varsity team") into 12 of the 14 key managerial positions. According to Barlett and Wozny (2005), all of these managers had invested in and agreed with Welch's "strong commitment to the new management values and a willingness to break with the old GE culture." With his followers in position, Welch further showed his ability to identify shifts and emerging opportunities from anticipating globalization of business in the eighties to adopting e-business before others did. Together, these played a significant part in revitalizing GE.

At the economy-wide level, implementing reform requires a combination of spotting appropriate 'windows of opportunity' as well as the persuasion of firms, unions, workers and other groups to invest in the reform. Examples range from the initiation of reform by Carlos Lleras Restrepo in Colombia and Narasimha Rao in India to Bill Clinton persuading various interest groups to sign onto NAFTA. In each of these instances, the set of technologically productive firms, trained workers and other groups who are well prepared for global integration constitute the set of committed followers. If circumstances look propitious and support for reform is large enough then enough others (the non-follower participants in our model) may also be persuaded to join the process of 
reform. The following episode illustrates one such instance of persuasion by a leader.

Resuscitating Economic Reform: Deng Xiaoping's Southern Tour. In the early nineties, the future of economic reform in post-Tiananmen China was seriously in doubt. The collapse of the Soviet Union had strengthened the hands of Chen Yun and the leftist ideologues at the expense of Deng and the reformers. Both in the media as well as within the party there was a concerted attempt to discredit Deng's policies of reform. Deng realized that winning the political (and ideological) debate within the higher echelons of the party was difficult and that he would need to mobilize support for reforms by directly addressing his followers. He further recognized that communication with the people was particularly difficult in Beijing due to the tight party control over the media.

Accordingly, Deng undertook the unprecedented 'Southern Tour' when he travelled to the Southern provinces in general and Guangdong and Shanghai in particular (Ash and Kueh, 1996). Deng's leadership ability showed in his quick identification of the difficulties of trying to garner support in Beijing. As pointed out by Zhao (1993), while Deng's skill in choosing both the right time and place to take on the central party hierarchy was important, success would not have been possible were it not for his confidence in the support of his followers in these regions - the direct beneficiaries of the reforms. Deng emphasized the importance of broad based economic development and reform to communicate with his followers and the lower level hierarchy in the party, using it as a way to criticize (and isolate) the ideological hardliners (Naughton, 1993). The response to Deng's appeal by both his followers and non-followers was immediate. It mobilized opinion and put pressure on the party hierarchy; thousands of cables and letters poured into Beijing party headquarters expressing support for Deng's policies. Not surprisingly, Deng's Southern Tour is widely regarded as single-handedly shifting the political momentum decisively and irreversibly in favor of the continuation of economic reform in China.

\section{Conclusion}

Leaders are ubiquitous across societies and organizations and have often been central to the transformation of organizations, political institutions and in many instances of social and economic reform. In this paper we took a first step towards analyzing the role of leadership in catalyzing large-scale change. Our analysis emphasizes that in order to understand effective leadership, it is important to focus on the nature of the relationship between a leader and his followers in transforming the prospects for change. The two-way interaction between followership and the supply of leadership initiative can endogenously give rise to threshold effects, with slight differences in the underlying structural conditions or in the leaders's ability resulting in dramatic differences in the prospects for change. Further the model shows that under a broad set of conditions, the 
populace may deliberately prefer to follow an ambitious leader whose interests may not always be congruent with theirs. As a result, while such leaders are more likely to bring about change, this change may often not be in the best interests of the majority. Thus our analysis also throws light on why 'good' as well as 'bad' leaders may both have their followers.

However our analysis is but a first step. Our framework explored only the broad contours of the impact of leaders in encouraging followership and participation to bring about change. Several other important elements of the process are obvious directions for future study. For instance, while the mode of change (captured by parameters such as the uncertainty of the process $p$, the gains $G$ and the costs to change $c$ ) is taken as given in our model, an important aspect of leadership is perhaps in choosing the right instrument for change. For example, in the context of political change, violent insurgency, peaceful demonstrations or strategic propaganda could be several possible means to achieve the same end. The leader's role would then be to determine which of these instruments would be the most appropriate under the given circumstances. A second aspect of leadership which has not been studied explicitly in our model (except in the welfare comparisons for different types of leaders) is leader selection. For example, if there were different individuals espousing different paths to change, who gets selected as the leader and how does this depend on the underlying environment? Or if there are multiple leaders, what is the dynamics of followership across the leaders and what is the impact on the overall chances for change? Aspects of the leader-follower relationship also deserve to be explored further. As pointed out by Levi (2006), 'leaders have the power to misinform and to manipulate, but they also have the power to inspire change'. In this context it would be useful to analyze in more detail the psychological and emotional underpinnings of the leader-follower relationship.

\section{References}

Acemoglu, Daron, Simon Johnson and James Robinson (2005), "Institutions as the Fundamental Cause of Long-run Economic Growth" in Philippe Aghion and Stephen Durlauf (ed) Handbook of Economic Growth, vol. 1A, North Holland, pp. 386-472.

Acemoglu, Daron, Simon Johnson and James Robinson (2003), "An African Success Story: Botswana"

in Dani Rodrik (ed) In Search of Prosperity: Analytic Growth Narratives, Princeton, pp. 80-122.

Acemoglu, Daron and James Robinson (2006), Economic Origins of Dictatorship and Democracy, Cambridge University Press.

Aghion, Philippe and Jean Tirole (1997), "Formal and Real Authority in Organizations". Journal of Political Economy, Vol. 105(1), pp. 1-29.

Ash, Robert and Y.Y. Kueh (1996), The Chinese Economy Under Deng Xiaoping, Oxford Uni- 
versity Press, USA.

Bartlett, C. and Meg Wozny (2005), “GE's Two-Decade Transformation: Jack Welch's Leadership", HBS Case Study, Harvard, Boston.

Besley, Timothy (2005), "Political Selection" Journal of Economic Perspectives, Vol. 19(3), pp. 43-60.

Besley, Timothy and Maitreesh Ghatak (2005), "Competition and Incentives with Motivated Agents". American Economic Review, Vol. 95(3), pp. 616-636.

Besley, Timothy and Masa Kudamatsu (2007), "Making Autocracy Work". Working paper, London School of Economics.

Brustein, William (1996), The Logic of Evil: The Social Origins of the Nazi Party 1925-1933, Yale University Press, New Haven.

Burns, James MacGregor (1978), Leadership, Harper and Row, New York.

Caro, Robert (2002), The Years of Lyndon Johnson: Master of the Senate, A. Knopf, New York.

Carlyle, Thomas (1904), On Heroes, Hero-Worship, and the Heroic in History, Oxford University Press, London.

Dalton, Dennis (1993), Mahatma Gandhi: Non-Violent Power in Action, Columbia University Press, New York

Dewatripont, Mathias and Jean Tirole (2005); "Modes of Communication", Journal of Political Economy 113(6), pp. 1217-1238.

Dixit, Avinash (2004), Lawlessness and Economics: Alternative Modes of Governance, Princeton University Press

Ferguson, Thomas and Hans-Joachim Voth (2008); "Betting on Hitler: The Value of Political Connections in Nazi Germany", Quarterly Journal of Economics 123(1), pp. 101-37.

Gilpin, Robert (1981), War and Change in World Politics, Cambridge University Press, New York Gray, Clive and Malcolm McPherson (2001), "The Leadership Factor in African Policy Reform and Growth Economic Development and Cultural Change, Vol. 49(4), pp. 707-740.

Harberger, Arnold (1993), "Secrets of Success: A Handful of Heroes" American Economic Review, vol. 83(2), pp. 343-50..

Hermalin, Benjamin (1998); "Towards an Economic Theory of Leadership: Leading by Example", American Economic Review vol. 88(5), pp. 1188-1206.

Hermalin, Benjamin, Mana Komai and Mark Stegeman (2006); "Leadership and Information", forthcoming, American Economic Review.

Hirschman, Albert (1970), "Underdevelopment, Obstacles to Perception of Change and Leadership" in Dankwart Rustow (ed.) Philosophers and Kings: Studies in Leadership, The Daedalus Library, New York. 
Ionescu, Ghita (1991), Leadership in an Interdependent World: The Statesmanship of Adenauer, De Gaulle, Thatcher, Reagan and Gorbachev, Westview, Boulder.

Jones, Benjamin and Benjamin Olken (2005); "Do Leaders Matter? National Leadership and Growth since World War II", Quarterly Journal of Economics 120(3), pp. 835-64.

Jones, Benjamin and Benjamin Olken (2006); "Hit or Miss? The Effect of Assasinations on Institutions and War", Working Paper, Harvard University.

Kissinger, Henry (1968), "The White Revolutionary: Reflections on Bismarck", Daedalus 97(3), pp. 888-924.

Kotter, John (2007), "Leading Change: Why Transformation Efforts Fail", Harvard Business Review, Boston.

Krause, J and G.D. Ruxton (2002), Living in Groups, Oxford University Press, Oxford.

Kravchenko, Victor (1946), I Chose Freedom, Garden City Publishing, New York

Levi, Margaret (2006), "Why We Need a New Theory of Government", Perspectives on Politics Presidential Address

Morris, Stephen and Hyung Song Shin (2003), "Global Games: Theory and Applications", in M. Dewatripont, L. Hansen and S. Turnovsky (ed.) Advances in Economics and Econometrics, Cambridge University Press, pp. 56-114.

Naughton, Barry (1993), "Deng Xiaoping: The Economist" The China Quarterly, Vol. 135, pp. 491-514.

Northouse, P.G. (2004), Leadership: Theory and Practice, Sage, CA.

Rodrik, D., A. Subramaniam and F. Trebbi (2002), "Institutions Rule: The Primacy of Institutions over Geography in Economic Development", Journal of Economic Growth, vol. 9(2).

Rotemberg, Julio and Garth Saloner (1993), "Leadership Style and Incentives". Management Science, Vol. 39, pp. 1299-1318.

Service, Robert (2000), Lenin: A Biography, New York, Macmillan.

Thyssen, Fritz (1941), I Paid Hitler, New York, Farrar and Rinehart.

Van Vugt, Mark (2006), "The evolutionary origins of leadership and followership", Personality and Social Psychology Review, Vol. 10, pp. 354-72.

Van Vugt, M., \& De Cremer, D. (1999). "Leadership in social dilemmas: The effects of group identification on collective actions to provide public goods." Journal of Personality and Social Psychology, vol. 76, pp. 587-99.

Willmer, Ann Ruth (1984), The Spellbinders, Yale University Press, New Haven.

Wilson, E.O. (1975), Sociobiology: The New Synthesis, Harvard University Press, Boston.

Young, Oran (1991), "Political Leadership and Regime Formation: On the Development of Institutions in International Society", International Organization, vol 45, pp. 281-308. 


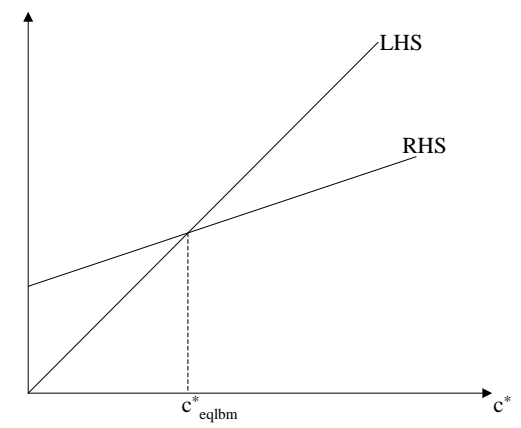

Figure 5: Equilibrium level of participation, $c^{*}$

Zhao Suisheng (1993), "Deng Xiaoping's Southern Tour" Asian Survey. Vol. 33(8), pp. 739-56.

\section{Appendix: Proofs}

Proof of Propostion 1: Consider equation (1) for a given level of $y>0$. At $c^{*}=0$, the $L H S$ is less than the RHS as $y>0$. At $c^{*}=c_{H}$, the $R H S=p \tau G<c_{H}=L H S$ (by assumption 1). Both sides of the equation are linear in $c^{*}$ (and are as depicted in figure 2); thus there is a unique solution to the equation in the range $c^{*} \in\left[0, c_{H}\right]$.

The probability of successful change in state $G_{1}$ is given by:p $\tau m^{e}=p \tau\left[y+(1-y) \frac{c^{*}}{c_{H}}\right]=\frac{c^{*}}{G}$. The two sides of equation (1) are depicted in figure 5. Increases in $y, p, G$ or $\tau$ or a decrease in $c_{H}$ raise the $R H S$ of (1) but have no effect on the $L H S$, and thus from the figure, result in an increase in $c^{*}$. Hence, these changes in the underlying parameters raise the probability of successful change in state $G_{1}$.

\section{Derivation of the OVERALL EQUILIBRIUM:}

Incorporating (from (2)) $i=\alpha a p \tau\left[y+(1-y) \frac{c^{*}}{c_{H}}\right] L_{1} / l=\frac{\alpha a L_{1}}{l G} c^{*}$ into (4) characterizes for a given level of $c^{*}$, the degree of investment into followership by any individual:

$$
\frac{(\alpha a)^{2} L_{1} \tau}{l G}\left(c^{*}\right)^{2}\left(1-\frac{c^{*}}{2 c_{H}}\right)=k y
$$

Given that the population is a continuum, if each individual invests $y$ in followership, then $y$ is also the fraction of the population with realized cost of participation $c=0$ i.e. it is the fraction of committed followers. For a given level of followership $y$, the degree of participation by the general populace is given by the equilibrium condition (1):

$$
p \tau\left[y+(1-y) \frac{c^{*}}{c_{H}}\right] G=c^{*} \quad \Longrightarrow \quad y\left(1-\frac{c^{*}}{c_{H}}\right)=c^{*}\left(\frac{1}{p \tau G}-\frac{1}{c_{H}}\right)
$$


Incorporating this into (13) gives the overall equilibrium condition for the model, equation $(5)^{26}$ :

$$
\frac{(\alpha a)^{2} L_{1} \tau}{l G k}\left(c^{*}\right)^{2}\left(1-\frac{c^{*}}{c_{H}}\right)\left(1-\frac{c^{*}}{2 c_{H}}\right)=c^{*}\left(\frac{1}{p G \tau}-\frac{1}{c_{H}}\right)
$$

Proof of Proposition 2: Consider equation (5). Clearly $c^{*}=0$ is a solution. Eliminating a $c^{*}$ from both sides, we see that while the $R H S$ is independent of $c^{*}$, the $L H S$ has three roots, at $c^{*}=0, c_{H}$ and $2 c_{H}$. In the relevant range i.e. between $c^{*}=0$ and $c^{*}=c_{H}$, it is inverse U-shaped. Thus, as depicted in figure 2(b), there will be either two solutions to equation (5) (case 1 in the figure) or none (case 2 in the figure, in which case there is no interior equilibrium, and the only equilibrium involves $c^{*}=0, y=0$ and $\left.i=0\right)$.

Which case occurs thus depends on whether or not the $R H S$ is greater or less than the highest point of the $L H S$. In the range $c^{*} \in\left[0, c_{H}\right]$, the maximum of the $L H S$ occurs at $c^{*}=c_{H}\left(1-\frac{1}{\sqrt{3}}\right)$, and its value at that point is $\frac{(\alpha a)^{2} L_{1} \tau c_{H}}{3 \sqrt{3} l G k}$. Whether or not this exceeds the $R H S$ is given by (6).

Derivation of Equilibrium for a general $\theta$ :

Again starting from period 2, the cutoff cost for the marginal non-follower is given by equating the costs and expected benefits of undertaking action:

$$
c^{*}=\frac{p \tau}{\theta}\left[y+(1-y) \frac{c^{*}}{c_{H}}\right]^{\theta} G
$$

Under assumption $2^{\prime},(15)$ always has a unique interior solution for any $y>0$.

In period 1, the leader's problem of how much to invest in acquiring information about the appropriateness of the current situation is almost identical to that before, and is characterized by the first-order condition: $\frac{\alpha a p \tau}{\theta}\left[y+(1-y) \frac{c^{*}}{c_{H}}\right]^{\theta} L_{1}=l i$ or using $(15), i=\alpha a L_{1} c^{*} /(G l)$.

Finally, the period 0 problem of deciding on followership is identical to the previous analysis, and thus the optimal choice of $y$ is again given by: $\alpha a i \tau\left[c^{*}-\frac{\left(c^{*}\right)^{2}}{2 c_{H}}\right]=k y$.

As before, using $y$ from (15) and $i=\alpha a L_{1} c^{*} /(G l)$, we can rearrange the above first-order condition to obtain the overall equilibrium condition for $c^{*}$ :

$$
\frac{(\alpha a)^{2} L_{1} \tau}{l G k}\left(c^{*}\right)^{2}\left(1-\frac{c^{*}}{c_{H}}\right)\left(1-\frac{c^{*}}{2 c_{H}}\right)=c^{*}\left(\left(\frac{\theta}{p G \tau}\right)^{\frac{1}{\theta}}\left(c^{*}\right)^{\frac{1}{\theta}-1}-\frac{1}{c_{H}}\right)
$$

\footnotetext{
${ }^{26}$ Equation (5) characterizes the overall equilibrium in the case where the elite group is of zero mass. Suppose instead the elite had a small but positive mass given by $n_{e}$, while that for the majority is $n_{m}=1-n_{e}$. It can be shown that in this case, the overall equilibrium is characterized by:

$$
\frac{\alpha^{2} L \tau}{l G k}\left(c^{*}\right)^{2}\left[n_{e}\left(1-\frac{c^{*}}{c_{H}}\right)\left(1-\frac{c^{*}}{2 c_{H}}\right)+a n_{m}\left(1-\frac{a c^{*}}{c_{H}}\right)\left(1-\frac{a c^{*}}{2 c_{H}}\right)=c^{*}\left(\frac{1}{p G \tau}-\frac{n_{e}+a n_{m}}{c_{H}}\right)\right.
$$

which is very similar in its properties as equation (5). Thus, the threshold effect holds here too.
} 
Solutions to this equation (if any) characterize equilibria for the overall game here.

Proof of Corollary 1: Clearly $c^{*}=0$ is a solution to (7) and is an equilibrium here too. To look for interior equilibria, we eliminate a $c^{*}$ from both sides of (7). The $L H S$ now is the same as that of $(5)$ and thus between $c^{*}=0$ and $c^{*}=c_{H}$, it is inverse U-shaped (as in figure 2(b)).

The RHS however is different and depends on $\theta$. For $\theta<1, \frac{1}{\theta}-1>0$, and thus the $R H S=$ $\left(\frac{\theta}{p G \tau}\right)^{\frac{1}{\theta}}\left(c^{*}\right)^{\frac{1}{\theta}-1}-\frac{1}{c_{H}}$ is increasing in $c^{*}$. At $c^{*}=0, R H S=-\frac{1}{c_{H}}<0=L H S$. While at $c^{*}=c_{H}$, $R H S=\frac{1}{c_{H}}\left(\left(\frac{\theta c_{H}}{p G \tau}\right)^{\frac{1}{\theta}}-1\right)>0=L H S$ (by assumption $\left.2^{\prime}\right)$. Thus there is always at least one interior solution to (7). In other words, for $0<\theta<1$, in addition to the no-action equilibrium, there always exists an interior equilibrium with a positive probability of change.

For $\theta>1, \frac{1}{\theta}-1<0$ and hence the $R H S$ is decreasing in $c^{*}$. Note that the $L H S$ is inverse U-shaped and attains its maximum value at $c^{*}=c_{H}\left(1-\frac{1}{\sqrt{3}}\right)$, where its value is $\frac{(\alpha a)^{2} L_{1} \tau c_{H}}{3 \sqrt{3} l G k}$. The minimum for the $R H S$ occurs at $c^{*}=c_{H}$ where its value is $\frac{1}{c_{H}}\left(\left(\frac{\theta c_{H}}{p G \tau}\right)^{\frac{1}{\theta}}-1\right)$.

Thus if $\frac{(\alpha a)^{2} L_{1} \tau c_{H}}{3 \sqrt{3} l G k}<\frac{1}{c_{H}}\left(\left(\frac{\theta c_{H}}{p G \tau}\right)^{\frac{1}{\theta}}-1\right)$, there will be no interior solution for the equilibrium condition (7) which implies that in this case the only equilibrium is the no-action one.

Proof of Proposition 3: We first use the solution of $c^{*}$ from (8) to rewrite $P_{1}$ as:

$$
P_{1}(\lambda)=\frac{\alpha a y^{2} L}{l G^{2}} \frac{1}{\widehat{a}\left[\frac{1}{p \tau G}-\frac{(1-y) \widehat{a}}{c_{H}}\right]^{2}}
$$

Denote $f(\widehat{a})=\widehat{a}\left[\frac{1}{p \tau G}-\frac{(1-y) \widehat{a}}{c_{H}}\right]^{2}$; we find that $f^{\prime}(\widehat{a}) \gtrless 0$ according as $\frac{c_{H}}{3(1-y) p \tau G} \gtrless \widehat{a}$. Since $P_{1}$ is inversely related to $f(\widehat{a})$, and $\widehat{a}$ is increasing in $\lambda$, this establishes the result.

Proof of Proposition 4: Eliminating a $c^{*}$, the $L H S$ of both (5) and (12) can be written as $\frac{\alpha^{2} L \tau}{l G k} c^{*}\left(1-\frac{c^{*}}{c_{H}}\right)\left(1-\frac{c^{*}}{2 c_{H}}\right)$, implying that it is inverse U-shaped, as in Figure 2(b).

The $R H S$ of (5) is then $\left(\frac{1}{p G \tau}-\frac{1}{c_{H}}\right) / a^{2}$, while that for (12) is $\frac{1}{p G \tau}-\frac{a}{c_{H}}$. Comparing the two, the RHS of (5) is bigger or less than the RHS of (12) according as $c_{H} \gtrless p G \tau\left(1+\frac{a^{2}}{1+a}\right)$.

Now $\frac{a^{2}}{1+a}$ is increasing in $a$, and has a maximum value of $1 / 2$. Thus, if $c_{H}>\frac{3}{2} p G \tau$, then the $R H S$ of (5) is always bigger than the RHS of (12) and therefore the threshold for a benevolent leader is more stringent.

On the other hand, if $c_{H}<\frac{3}{2} p G \tau$, there exists an $a^{*} \in(0,1)$ at which $c_{H}=p G \tau\left(1+\frac{\left(a^{*}\right)^{2}}{1+a^{*}}\right)$. Below $a^{*}, c_{H}>p G \tau\left(1+\frac{a^{2}}{1+a}\right)$ i.e. the $R H S$ of (5) is bigger than the $R H S$ of (12), meaning that the threshold for a benevolent leader is more stringent. For $a>a^{*}$, the reverse holds and the threshold is more stringent for a self-interested leader. 
Proof of Proposition 5: To derive the ex-ante welfare $W_{B}$ under a benevolent leader, we take the period 0 payoff from (3) and plug back the optimal $y$ from (4) together with the leader's equilibrium choice $i_{B}=\frac{\alpha a L_{1}}{l G} c^{*}$ to get:

$$
W_{B}=a^{2} \frac{\alpha^{2} L_{1} \tau}{2 l G} \frac{\left(c^{*}\right)^{3}}{c_{H}}+a^{4} \frac{1}{2 k}\left\{\frac{\alpha^{2} L_{1} \tau}{l G}\left(c^{*}\right)^{2}\left(1-\frac{c^{*}}{2 c_{H}}\right)^{2}\right\}^{2}
$$

Similarly the ex-ante welfare $W_{S}$ under a self-interested leader is derived by plugging in the optimal $y$ from (11) into (10) to obtain:

$$
W_{S}=\frac{\alpha^{2} L_{1} \tau}{2 a l G} \frac{\left(c^{*}\right)^{3}}{c_{H}}+\frac{1}{2 k}\left\{\frac{\alpha^{2} L_{1} \tau}{a l G}\left(c^{*}\right)^{2}\left(1-\frac{c^{*}}{2 c_{H}}\right)^{2}\right\}^{2}
$$

Note that for a given $c^{*}, W_{B}<W_{S}$ for all $a<1$ and as expected are equal for $a=1$. Also note that $W_{B}$ and $W_{S}$ are both increasing in $c^{*}$; thus, if $c^{*}$ under a self-interested leader is bigger than that under a benevolent leader, $W_{S}$ will exceed $W_{B}$.

To compare the equilibrium $c^{*}$ under the two types of leaders, let us rewrite the two equilibrium conditions:

$$
\begin{aligned}
\frac{\alpha^{2} L \tau}{l G k} c^{*}\left(1-\frac{c^{*}}{c_{H}}\right)\left(1-\frac{c^{*}}{2 c_{H}}\right) & =\frac{1}{a^{2}}\left(\frac{1}{p G \tau}-\frac{1}{c_{H}}\right) \\
\frac{\alpha^{2} L \tau}{l G k} c^{*}\left(1-\frac{c^{*}}{c_{H}}\right)\left(1-\frac{c^{*}}{2 c_{H}}\right) & =\left(\frac{1}{p G \tau}-\frac{a}{c_{H}}\right)
\end{aligned}
$$

The left-hand side of both are identical and represent an inverse U-shaped function of $c^{*}$ as depicted in figure 2. The right hand side of both are constant and whether the Pareto-dominant equilibrium $c^{*}$ under a self-interested leader exceeds that under a benevolent leader depends on if $\frac{1}{a^{2}}\left(\frac{1}{p G \tau}-\frac{1}{c_{H}}\right)>\frac{1}{p G \tau}-\frac{a}{c_{H}}$ i.e. if $c_{H}>p G \tau\left(1+\frac{a^{2}}{1+a}\right)$.

If $c_{H}>\frac{3}{2} p G \tau$, then this holds for all $a \in[0,1]$, while if $c_{H}<\frac{3}{2} p G \tau$, it holds for $a$ small enough. Thus in either of these two cases, the (Pareto-dominant) equilibrium $c^{*}$ under a self-interested leader is higher than that under a benevolent leader, and consequently the ex-ante welfare under a self-interested leader $W_{S}$ is greater than that under a benevolent leader $W_{B}$. 


\section{CESifo Working Paper Series}

for full list see www.cesifo-group.org/wp

(address: Poschingerstr. 5, 81679 Munich, Germany, office@cesifo.de)

2273 Thor Olav Thoresen and Annette Alstadsæter, Shifts in Organizational Form under a Dual Income Tax System, April 2008

2274 Helge Berger and Volker Nitsch, Too many Cooks? Committees in Monetary Policy, April 2008

2275 Yin-Wong Cheung and Eiji Fujii, Deviations from the Law of One Price in Japan, April 2008

2276 Michael S. Michael, Sajal Lahiri and Panos Hatzipanayotou, Integrated Reforms of Indirect Taxes in the Presence of Pollution, April 2008

2277 Bas Jacobs, Is Prescott Right? Welfare State Policies and the Incentives to Work, Learn and Retire, April 2008

2278 Burkhard Heer and Alfred Maußner, Value Function Iteration as a Solution Method for the Ramsey Model, April 2008

2279 Jarko Fidrmuc and Christa Hainz, Integrating with their Feet: Cross-Border Lending at the German-Austrian Border, April 2008

2280 Kristof Dascher and Alexander Haupt, The Political Economy of Regional Integration Projects at Borders where Rich and Poor Meet: The Role of Cross-Border Shopping and Community Sorting, April 2008

2281 Katrin Assenmacher-Wesche and M. Hashem Pesaran, A VECX* Model of the Swiss Economy, April 2008

2282 Christophe Rault, Robert Sova and Ana Maria Sova, Modeling International Trade Flows between CEEC and OECD Countries, April 2008

2283 Timo Boppart, Josef Falkinger, Volker Grossmann, Ulrich Woitek and Gabriela Wüthrich, Qualifying Religion: The Role of Plural Identities for Educational Production, April 2008

2284 Armin Falk, David Huffman and W. Bentley MacLeod, Institutions and Contract Enforcement, April 2008

2285 Axel Dreher and Stefan Voigt, Does Membership in International Organizations Increase Governments' Credibility? Testing the Effects of Delegating Powers, April 2008

2286 Xavier Freixas and Bruno M. Parigi, Lender of Last Resort and Bank Closure Policy, April 2008 
2287 Regina Dionisius, Samuel Muehlemann, Harald Pfeifer, Günter Walden, Felix Wenzelmann and Stefan C. Wolter, Cost and Benefit of Apprenticeship Training - A Comparison of Germany and Switzerland, April 2008

2288 Francesco Daveri and Cecilia Jona-Lasinio, Off-Shoring and Productivity Growth in the Italian Manufacturing Industries, April 2008

2289 Mikael Priks, Do Surveillance Cameras Affect Unruly Behavior? A Close Look at Grandstands, April 2008

2290 Marianna Belloc and Daniela Federici, A Two-Country NATREX Model for the Euro/Dollar, April 2008

2291 Nicolas Treich, The Value of a Statistical Life under Ambiguity Aversion, April 2008

2292 J. Atsu Amegashie, Socially-Tolerable Discrimination, April 2008

2293 M. Hashem Pesaran and Andreas Pick, Forecasting Random Walks Under Drift Instability, April 2008

2294 Steven Brakman, Gus Garita, Harry Garretsen and Charles van Marrewijk, Unlocking the Value of Cross-Border Mergers and Acquisitions, May 2008

2295 Eric O’N. Fisher and Kathryn G. Marshall, The Structure of the American Economy, May 2008

2296 Claudia M. Buch and Martin Schlotter, Regional Origins of Employment Volatility: Evidence from German States, May 2008

2297 Helmuth Cremer, Philippe De Donder, Dario Maldonado and Pierre Pestieau, Taxing Sin Goods and Subsidizing Health Care, May 2008

2298 Reinhilde Veugelers and Frederick van der Ploeg, Reforming European Universities: Scope for an Evidence-Based Process, May 2008

2299 Jon H. Fiva and Lars J. Kirkebøen, Does the Housing Market React to New Information on School Quality?, May 2008

2300 Tina Klautke and Alfons J. Weichenrieder, Interest Income Tax Evasion, the EU Savings Directive, and Capital Market Effects, May 2008

2301 Harald Badinger and Peter Egger, GM Estimation of Higher Order Spatial Autoregressive Processes in Panel Data Error Component Models, May 2008

2302 Jan K. Brueckner, Slot-Based Approaches to Airport Congestion Management, May 2008

2303 Sören Blomquist, Vidar Christiansen and Luca Micheletto, Public Provision of Private Goods and Nondistortionary Marginal Tax Rates, May 2008 
2304 Dan Anderberg and Alessandro Balestrino, The Political Economy of Post-Compulsory Education Policy with Endogenous Credit Constraints, May 2008

2305 Tomer Blumkin, Yoram Margalioth and Efraim Sadka, The Role of Stigma in the Design of Welfare Programs, May 2008

2306 Vesa Kanniainen and Paolo M. Panteghini, Tax Neutrality: Illusion or Reality? The Case of Entrepreneurship, May 2008

2307 Thomas Dohmen, Armin Falk, David Huffman and Uwe Sunde, The Intergenerational Transmission of Risk and Trust Attitudes, May 2008

2308 Guglielmo Maria Caporale and Mario Cerrato, Using Chebyshev Polynomials to Approximate Partial Differential Equations, May 2008

2309 Peter Egger and Doina Maria Radulescu, Labour Taxation and Foreign Direct Investment, May 2008

2310 Laurent Linnemer, Dissipative Advertising Signals Quality even without Repeat Purchases, May 2008

2311 Jordi Jofre-Monseny and Albert Solé-Ollé, Which Communities should be afraid of Mobility? The Effects of Agglomeration Economies on the Sensitivity of Firm Location to Local Taxes, May 2008

2312 Andreas Haufler and Ferdinand Mittermaier, Unionisation Triggers Tax Incentives to Attract Foreign Direct Investment, May 2008

2313 Ronel Elul and Piero Gottardi, Bankruptcy: Is it enough to Forgive or must we also Forget?, May 2008

2314 Andreas Irmen and Johanna Kuehnel, Productive Government Expenditure and Economic Growth, May 2008

2315 Beate Henschel, Carsten Pohl and Marcel Thum, Demographic Change and Regional Labour Markets: The Case of Eastern Germany, May 2008

2316 Gabriel Felbermayr, Wido Geis and Wilhelm Kohler, Restrictive Immigration Policy in Germany: Pains and Gains Foregone?, May 2008

2317 Michael Hofmann, Gerhard Kempkes and Helmut Seitz, Demographic Change and Public Sector Budgets in a Federal System, May 2008

2318 Paul De Grauwe, Macroeconomic Modeling when Agents are Imperfectly Informed, June 2008

2319 Johann K. Brunner and Susanne Pech, Optimum Taxation of Inheritances, June 2008

2320 Thomas Eichner and Marco Runkel, Corporate Income Taxation of Multinationals in a General Equilibrium Model, June 2008 
2321 Rainald Borck and Matthias Wrede, Subsidies for Intracity and Intercity Commuting, June 2008

2322 Patricia Apps and Ray Rees, Testing the Pareto Efficiency of Household Resource Allocations, June 2008

2323 Amihai Glazer, Vesa Kanniainen and Panu Poutvaara, Firms' Ethics, Consumer Boycotts, and Signalling, June 2008

2324 Claudia M. Buch, Jörg Döpke and Kerstin Stahn, Great Moderation at the Firm Level? Unconditional vs. Conditional Output Volatility, June 2008

2325 Helmuth Cremer, Philippe De Donder, Dario Maldonado and Pierre Pestieau, Forced Saving, Redistribution and Nonlinear Social Security Schemes, June 2008

2326 M. Hashem Pesaran and Paolo Zaffaroni, Optimal Asset Allocation with Factor Models for Large Portfolios, June 2008

2327 Harald Badinger and Peter Egger, Horizontal versus Vertical Interdependence in Multinational Activity, June 2008

2328 Jan K. Brueckner and Harris Selod, A Theory of Urban Squatting and Land-Tenure Formalization in Developing Countries, June 2008

2329 Paolo M. Panteghini, Corporate Debt, Hybrid Securities and the Effective Tax Rate, June 2008

2330 Guglielmo Maria Caporale, Juncal Cuñado and Luis A. Gil-Alana, Modelling Long-Run Trends and Cycles in Financial Time Series Data, June 2008

2331 Avi Ben-Bassat and Momi Dahan, Social Identity and Voter Turnout, June 2008

2332 Martin R. West and Ludger Wößmann, "Every Catholic Child in a Catholic School”: Historical Resistance to State Schooling, Contemporary Private Competition, and Student Achievement across Countries, June 2008

2333 Erkki Koskela and Panu Poutvaara, Outsourcing and Labor Taxation in Dual Labor Markets, June 2008

2334 Philippe Choné and Laurent Linnemer, Optimal Litigation Strategies with Signaling and Screening, June 2008

2335 Albert Solé-Ollé and Pilar Sorribas-Navarro, Does Partisan Alignment Affect the Electoral Reward of Intergovernmental Transfers?, June 2008

2336 Antonio Cabrales and Piero Gottardi, Markets for Information: Of Inefficient Firewalls and Efficient Monopolies, June 2008

2337 Sumon Majumdar and Sharun W. Mukand, The Leader as Catalyst - on Leadership and the Mechanics of Institutional Change, June 2008 